\title{
Practical Considerations for Reliable Stress and Oxygen Surface Exchange Coefficients from Bilayer Curvature Relaxation Measurements
}

\author{
Dr. Jason D. Nicholas \\ Chemical Engineering \& Materials Science Department, Michigan State University, \\ 428 South Shaw Lane, 2527 Engineering Building, East Lansing, MI 48824, USA
} Phone: (517) 355-1615 Email: jdn@,msu.edu Web: https://www.egr.msu.edu/nicholasgroup/

\begin{abstract}
The curvature relaxation technique is a new electrode-free method for simultaneously measuring a material's chemical oxygen surface exchange coefficient and stress state under controlled atmosphere and temperature conditions. Provided certain conditions are met, this in situ / in operando technique can be used to accurately measure the oxygen surface exchange coefficients and stress states of dense, porous, thin, or thick film oxygen exchange materials. The present paper provides a detailed, practical discussion of these conditions and compares the curvature relaxation technique to alternative oxygen surface exchange coefficient measurement approaches.
\end{abstract}

\section{Keywords}

Oxygen Surface Exchange; Curvature Relaxation; Chemical Strain; Chemical Stress; MechanoChemical Coupling; Thin Film; Mechano-Chemically Active; 


\section{Introduction}

Materials capable of quickly exchanging oxygen with the surrounding atmosphere are used in a variety of electrochemical devices such as solid oxide fuel cells (SOFCs), ${ }^{1-5}$ catalytic reactors, ${ }^{6,7}$ gas sensors, ${ }^{8}$ solar thermochemical fuel generators, ${ }^{7,9}$ and gas separation membranes. ${ }^{10,11}$ Many of the best performing oxygen exchange materials, such as those in Table 1, are mixed ionic electronic conducting (MIEC) materials that facilitate oxygen exchange through an internal change in cation oxidation state. For example, the oxygen exchange reaction in the MIEC material lanthanum strontium iron oxide (LSF) is:

$$
2 F e_{F e}^{\bullet}+O_{o}^{x} \rightarrow 1 / 2 O_{2(g)}+V_{o}^{\bullet \bullet}+2 F e_{F e}^{x}
$$

where, in the forward direction, lattice oxygen $\left(O_{o}^{x}\right)$ leaves the lattice to produce to produce oxygen gas $\left(O_{2(g)}\right)$ by creating an oxygen vacancy $\left(V_{o}^{\bullet \bullet}\right)$ and filling two iron-bound electron holes $\left(2 F e_{F e}^{\bullet}\right){ }^{12,13}$ A material's intrinsic ability to exchange oxygen is often quantified by its chemical oxygen surface exchange coefficient, $k$, which is the rate constant for a dominant oxygen exchange reaction like Equation 1.

Unfortunately, large disparities exist in the reported oxygen surface exchange coefficients of even the most common MIEC materials. For instance, literature reports indicate that there is a 2 orders of magnitude variation, a 3 order of magnitude variation, and a 4 order of magnitude variation in the $650^{\circ} \mathrm{C} k$ of $\mathrm{Ce}_{0.9} \mathrm{Gdd}_{0.1} \mathrm{O}_{1.95-\delta},{ }^{14}$ lanthanum strontium cobalt iron oxide $\left(\mathrm{La}_{0.6} \mathrm{Sr}_{0.4} \mathrm{Fe}_{0.8} \mathrm{Co}_{0.2} \mathrm{O}_{3-\delta}\right)^{15,16}$, and $\mathrm{La}_{0.6} \mathrm{Sr}_{0.4} \mathrm{FeO}_{3-\delta}(\mathrm{LSF} 64),{ }^{13,17-19}$ respectively. Many authors have suggested that some of this $k$ variation may be caused by varying MIEC stress/strain states, ${ }^{20}$ with density functional theory simulations predicting that experimentally-achievable thin film biaxial tensile strains of $1-2 \%^{21}$ can enhance ionic transport coefficients by up to 1000 times. $^{22,23}$ However, techniques capable of simultaneously measuring a material's $k$ and stress state have been 
missing from the literature. The present work provides practical advice for utilizing a new curvature relaxation $(\kappa R)$ technique ${ }^{19,24}$ that simultaneously measures a material's thicknessaveraged stress state and oxygen exchange coefficient under in situ/in operando conditions.

\section{Theoretical Considerations}

\section{$\underline{2.1 \text { Oxygen Surface Exchange Coefficient Measurements }}$}

The $\kappa R$ technique relies upon the lattice strain induced by changes in the oxygen nonstoichiometry, $\delta$, occurring as a result of oxygen exchange reactions like Equation 1 . Specifically, dense ${ }^{19}$ or porous ${ }^{24}$ films of mechano-chemically active materials (i.e. those that exhibit a change in strain due to a change in $\delta$ ) such as those in Table 1 are produced on inert substrates, heated, and subjected to small, sudden oxygen partial pressure $\left(\mathrm{pO}_{2}\right)$ changes. As shown in Figure 1a, in response to a new $\mathrm{pO}_{2}$, mechano-chemically active films bonded to inert substrates will strain as they adjust their oxygen nonstoichiometry, leading to a relaxation of the bilayer sample curvature that tracks the rate of oxygen exchange in the MIEC film.

Dense MIEC films with thicknesses less than $\sim 1 / 100^{\text {th }}$ of their characteristic thickness $\left(L_{C}\right)$ :

$$
L_{C}=D / k=R_{S} \sigma_{V_{O}}
$$

(where $D$ is the bulk chemical oxygen ion diffusivity, $R_{S}$ is the electrical surface resistance, and $\sigma_{V_{o}}$ is the bulk oxygen ion conductivity) have fast oxygen diffusion within the film compared to the rate at which oxygen leaves or enters the film via the surface exchange process. This ensures that no through-thickness $\delta$ gradients develop (even as the film equilibrates and the film $\delta$ changes) ${ }^{25,26}$ Hence, oxygen exchange in these films is completely controlled by oxygen surface exchange, allowing $k$ to be determined by fitting the observed curvature relaxation to the solution to Fick's Second Law for oxygen transport into or out a surface-controlled membrane: 


$$
\frac{\kappa-\kappa_{O}}{\kappa_{\infty}-\kappa_{o}}=\frac{c_{v}-c_{v_{O}}}{c_{v_{\infty}}-c_{v_{O}}}=1-\sum_{i=1}^{n} \mathrm{~A}_{i} \exp \left(-\frac{t k_{i}}{h_{f}}\right)
$$

where $\kappa, \kappa_{0}$, and $\kappa_{\infty}$ are the instantaneous, initial, and new $p O_{2}$-equilibrated sample curvatures, $c_{v}, c_{v o}$, and $c_{v \infty}$ are the instantaneous, initial, and new $p O_{2}$-equilibrated oxygen vacancy concentrations in the film, $\delta, \delta_{0}$, and $\delta_{\infty}$ are the instantaneous, initial, and new $p O_{2}$-equilibrated oxygen nonstoichiometries, $k_{i}$ is the surface exchange coefficient for a portion of the film with an area fraction $\mathrm{A}_{i}, t$ is time, and $h_{f}$ is the film thickness. ${ }^{19,27-31}$ Figure $1 \mathrm{~b}$ shows an example of using Equation 4 to fit measured $\kappa \mathrm{R}$ data.

Similarly, highly porous, well-necked MIEC films with particle sizes $(P)$ less than $\sim 1 / 100^{\text {th }}$ of $L_{C}$ can have their $\mathrm{k}$ be determined from the expression:

$$
\frac{\kappa-\kappa_{O}}{\kappa_{\infty}-\kappa_{o}}=\frac{c_{v}-c_{v_{O}}}{c_{v_{\infty}}-c_{v_{O}}}=1-\exp \left(-\frac{k t}{\frac{1-V_{V}}{S_{V}}}\right)
$$

where $V_{V}$ is the volume fraction porosity, $S_{V}$ is the specific pore surface area, and the other symbols have their previously defined meanings. ${ }^{24,32}$ (See Nicholas ${ }^{33}$ for a derivation of Equations 4 and 5).

Dense MIEC films with thicknesses greater than $\sim 1 / 100^{\text {th }}$ of $L_{C}$ and porous MIEC films with particle sizes greater than $\sim 1 / 100^{\text {th }}$ of $L_{C}$ have their curvature response controlled by both oxygen surface exchange into/out of the MIEC (quantified by $k$ ) and bulk transport within the MIEC (quantified by $D$ ). $\kappa R$ measurements on films with these geometries have not yet been attempted due to the inherent difficulty in accurately measuring both $k$ and $D$ from a single sample, ${ }^{26,34}$ and the fact that an oxygen vacancy concentration gradient through the thickness of the film complicate the existing relationships used to extract film stress from the bilayer curvature. However, with additional work, simultaneous $k$ and $D$ measurements on thick dense films or large grained porous films should be possible. 


\section{$\underline{2.2 \text { Film Stress Measurements }}$}

At any time in a $\kappa R$ experiment, the measured curvature can be converted into a biaxial film stress $(\lambda)$. In fact, this has been done in many past equilibrium in situ wafer curvature studies that were not configured to derive meaningful materials property data from transient (i.e. relaxation) curvature data. ${ }^{35-40}$ Specifically, for dense MIEC films with film to substrate thickness ratios $\leq 1: 1000$ this is accomplished using Stoney's Equation:

$$
\bar{\lambda}=\kappa \frac{M_{S} h_{S}^{2}}{6 h_{f}}
$$

where $\bar{\lambda}$ is the thickness-averaged film stress, $h_{s}$ is the substrate thickness and $M_{S}$ is the substrate biaxial modulus defined as $E_{S} /\left(1-v_{S}\right)$ where $E_{S}$ is substrate Young's modulus and $v_{S}$ is the substrate Poisson's Ratio. ${ }^{36,41}$ More generally, the biaxial stress for a dense film with an arbitrary $h_{f}: h_{S}$ ratio can be extracted from the bilayer curvature using the relationship:

$$
\lambda(z)=\kappa \frac{M_{S} h_{S}^{2}}{6 h_{f}}\left[\frac{a}{b}-\frac{M_{f} h_{f}}{b M_{S} h_{S}}\left(1+\frac{h_{f}^{3} M_{f}}{h_{S}^{3} M_{S}}\right)-\frac{6 h_{f}}{h_{S}^{2}} \frac{M_{f}}{M_{S}} z\right]
$$

where

$$
\begin{gathered}
a=\left(1+4 \frac{h_{f}}{h_{S}} \frac{M_{f}}{M_{S}}+6 \frac{h_{f}^{2}}{h_{S}^{2}} \frac{M_{f}}{M_{S}}+4 \frac{h_{f}^{3}}{h_{S}^{3}} \frac{M_{f}}{M_{S}}+\frac{h_{f}^{4}}{h_{S}^{4}} \frac{M_{f}^{2}}{M_{S}^{2}}\right) \\
b=\left(1+\frac{h_{f}}{h_{S}}\right)
\end{gathered}
$$

$\mathrm{z}$ is the film-normal distance from the substrate mid-plane, $M_{f}$ is the film biaxial modulus, and the other variables have their previously defined meanings. ${ }^{36,41}$ As seen by inspecting Equation 7 , $h_{f}: h_{S}$ ratios $\leq 1: 1000$ cause Equation 7 to collapse to Equation 6, and smaller $h_{f}: h_{S}$ ratios lead to less z-variation in film stress. Thankfully, even for dense films less than a few microns thick on $200 \mu \mathrm{m}$ thick yttria stabilized zirconia (YSZ) single crystal wafers, the errors in thickness- 
averaged film stress introduced by using Equation 6 instead of Equation 7 are typically less than a few percent. ${ }^{24}$ While Equations 6 and 7 can be used to determine the biaxial stress state within dense films as a function of thickness, they can only be used to estimate the thickness-averaged film stresses present in porous films containing microstructural features capable of locally concentrating or dissipating the average film stress.

\subsection{Practical Considerations}

\subsection{Curvature Measurement}

\subsubsection{In Situ/In Operando Curvature Measurement Setup}

Figures 2 and 3 provide schematic and photographic documentation of the experimental setup presently used to conduct $\kappa \mathrm{R}$ measurements. In this setup, a k-Space Associates (kSA, Dexter, MI) multi-beam optical sensor (MOS) generates a multi-spot (typically a 3 x 3 ) laser array with an inter-spot spacing of $d_{o}$ and array dimensions of 3-5 mm by passing light from a $25 \mathrm{~mW}$ fiber-coupled diode laser through 2 inclined etalons, each at right angles to each other. The laserbeam array then passes through a beam splitter, exits the kSA MOS optical housing, reflects off a table mounted $45^{\circ}$ mirror, passes through a quartz window and into a vacuum-evacuated fused silica tube, travels up into a vertically-mounted tube furnace, passes through another quartz window into the sample chamber, and then reflects off the polished surface of a multilayer sample. After reflecting off the sample with array-averaged incidence and reflection angles of $\theta$, the laser beam array passes once again through the quartz window and into the vacuum evacuated fused silica support tube, travels down the tube and out of the furnace, passes through the bottom quartz window and into ambient air, reflects off the table-mounted $45^{\circ}$ mirror, enters the kSA MOS optical housing, reflects off the beam splitter, and finally reflects off a rotatable mirror (which can 
be used to keep the array on the CCD as the sample curves, but often isn't necessary due to manual pitch and yaw knobs on the assembly holding the inner fused silica support tube) before passing through a bandpass filter and entering the CCD detector. As shown in Figure 1, a convex sample curvature causes the beams of the reflected array to diverge, while a concave sample curvature causes the beams of the reflected array to initially converge. Based on basic geometrical relationships, the sample curvature is calculated from the CCD-detected inter-spot spacing (d) using the relationship:

$$
\kappa=\left(\frac{\cos \theta}{2 L}\right)\left(1-\frac{d}{d_{o}}\right)
$$

where $L$ is the sample to $\mathrm{CCD}$ distance, and the other variables have their previously defined meanings. The inter-spot spacing is determined by capturing a CCD image with a frame-grabber and using proprietary k-Space algorithms to fit the observed laser beam positions. Before each measurement, $d_{o}$ is determined by measuring $d$ when a flat mirror $(\kappa=0)$ is placed in the sample location. Subsequently, $\frac{\cos \theta}{2 L}$ is determined by adjusting $\frac{\cos \theta}{2 L}$ until the software correctly measures curvature of a mirror with a known curvature (typically $\kappa=1 / 10 \mathrm{~m}$ ).

\subsubsection{Curvature Measurement Sensitivity}

For correct curvature measurements of concave samples via Equation 10, $L$ must be less than the reflected array convergence distance. Thankfully, this is never a problem given the small $\kappa$ of commercially available wafers (the wafers typically appear flat to the human eye and can be made even flatter through a recommended high temperature anneal of the as-received wafers). The inter-spot spacing CCD detector can be placed close to the sample to increase the $d$ of concave samples or further from the sample to increase the $d$ of convex samples. Literature studies have reported that resolvable room-temperature curvature changes of $\sim 0.0006 \mathrm{~m}^{-1}$ are possible with 
convenient $L$ and $\phi$ values of $66 \mathrm{~cm}$ and $3^{\circ}$, respectively. ${ }^{38}$ One benefit of using a multi-beam laser array (instead of a single laser beam) to measure sample curvature is that with a multi-beam array only the inter-spot spacing, $d$, and not the absolute laser spot positions on the CCD are required for an accurate curvature measurement. This ensures that curvature measurements conducted with a multi-beam array are less sensitive to vibrations and hence do not require active vibrationdamping controls to obtain a good curvature signal to noise ratio.

As demonstrated by the signal to noise ratio in Figure 1a, high-temperature curvature changes of $\sim 0.001 \mathrm{~m}^{-1}$ are resolvable with the $\kappa \mathrm{R}$ setup described here (with $L=100 \mathrm{~cm}$ and $\theta=3^{\circ}$ ). One key to obtaining good curvature resolution at elevated temperature is to limit laser beam travel through high temperature gases (temperature-induced index of refraction fluctuations and/or gradients within the gas alter $d$.) In the present $\kappa \mathrm{R}$ setup, laser beam travel through high temperature gasses is limited by resting the sample on an inner support tube that has been vacuum evacuated to $\sim 0.2 \mathrm{~Pa}$. Another key to obtaining well-resolved, high-temperature curvature measurements is to deploy a notch filter (a $10 \mathrm{~nm}$ wide notch filter is presently used) that keeps the laser-spots discernable by limiting the amount of stray blackbody radiation entering the CCD. Optimization of the CCD camera settings (gain, background threshold, etc.) may also be needed to ensure that all the kSA MOS laser spots remain distinguishable from the background. With a conventional red $(660 \mathrm{~nm})$ laser array, these techniques ensure that $\sim 0.001 \mathrm{~m}^{-1}$ resolution curvature measurements are possible from room temperature until $\sim 900^{\circ} \mathrm{C}$ (higher temperatures may be possible using smaller wavelength kSA MOS lasers). 


\subsection{Controlled Atmosphere Test Rig Design}

\subsubsection{Controlled Atmosphere Reactor Design \& Gas Handling}

As shown in Figure 4, a custom built, two-piece fused silica reactor consisting of an outer cover and an inner support tube is used to establish a controlled atmosphere around the sample while maintaining optical access. The outer reactor cover consists of a closed end, $27 \mathrm{~mm}$ inner diameter, $30 \mathrm{~mm}$ outer diameter fused silica tube bonded to a female Pyrex 34/45 tapered ground joint (Technical Glass Products; Painesville Twp, $\mathrm{OH}$ ). The reactor design is such that the fused silica portion of the reactor is exposed to high temperatures, while the Pyrex portion of the test rig rests outside the furnace hot zone. $\mathrm{A} \sim 3 \mathrm{~m}$ long gas preheating coil made from $6.35 \mathrm{~mm}$ diameter fused silica tubing wraps around the outer cover and directs preheated gas onto a $\kappa R$ sample, which rests approximately $6 \mathrm{~mm}$ below the closed end of the outer reactor cover when the test rig is fully assembled. Approximately $1.2 \mathrm{~m}$ of the gas-preheating coil exist in the furnace hot zone.

The inner sample support tube consists of a $20 \mathrm{~mm}$ inner diameter, $25 \mathrm{~mm}$ outer diameter fused silica tube axially bonded to a $19 \mathrm{~mm}$ inner diameter, $22 \mathrm{~mm}$ outer diameter fused silica tube. The thinner, $22 \mathrm{~mm}$ diameter end of this tube is then tucked inside an upward facing male 34/45 tapered Pyrex joint (Technical Glass Products; Painesville Twp, OH) and bonded to a fused silica window (Technical Glass Products; Painesville Twp, $\mathrm{OH}$ ) inclined at $4^{\circ}$ to the tube axis normal. This $4^{\mathrm{o}}$ inclination ensures that any back-reflections from the fused silica window do not enter the CCD detector within the MOS. A second $4^{\circ}$ inclined fused silica window is bonded to the upper portion of the inner support tube, and, as mentioned previously, the portion of the inner support tube between the two quartz windows is vacuum evacuated. A $6.35 \mathrm{~mm}$ diameter gas port in the Pyrex joint approximately $10 \mathrm{~mm}$ above the fused silica window provides an exit path for the process gas. 
The inner tube is designed so that enough distance between the bottom of the male ground glass joint and the top of the exit gas port exists for the inner support tube to be secured by a custom-made aluminum mounting block. As shown in Figure 3, this aluminum mounting block is bolted to a positioning system made up of a $\mathrm{x}$ translation stage (NT66-430, Edmund Optics; Barrington, NJ), a y translation stage (NT66-430, Edmund Optics; Barrington, NJ), a pitch goniometer (GON65-1, Newport Optics; Irvine CA) a yaw goniometer (GON65-u, Newport Optics; Irvine CA), a 90 mounting bracket (07-TSR-204 CVI Melles Griot; Albuquerque, NM), and an optical post assembly (07-DUP-011/07-DSQ-003, CVI Melles Griot; Albuquerque, NM). This inner tube positioning system is used to make the inner tube coaxial with the kSA MOS laser beam array that is reflected off a $45^{\circ}$ mounted (NT59-002, Edmund Optics; Barrington, NJ) $\lambda / 20$ Zerodur mirror (NT43-420-533, Edmund Optics; Barrington, NJ) attached to a micrometer stage (NT66-427, Edmund Optics; Barrington, NJ) that is designed to axially translate with original laser beam array exiting the MOS.

A removable $\sim 10 \mathrm{~mm}$ long piece of a $19 \mathrm{~mm}$ inner diameter, $25.4 \mathrm{~mm}$ outer diameter 99.8\% alumina tube (Coorstek; Golden, CO) rests atop the flat, ground surface at the top of the inner support tube. This alumina spacer ensures that $\kappa R$ samples do not become silica contained through direct contact with the inner support tube, and several $\sim 6 \mathrm{~mm}$ deep, $\sim 2 \mathrm{~mm}$ wide axialnormal oriented notches on top of the alumina spacer ensures adequate gas mixing beneath the sample (since some studies have shown that Si from a quartz reactor tube can degrade a material's $k$ at $600^{\circ} \mathrm{C},{ }^{42}$ when utilizing a silica test rig it is a good idea to minimize $\kappa \mathrm{R}$ analysis temperatures, check for reproducible $k$ values via multiple switching events with time, and/or perform postmortem X-ray Photoelectron studies to detect Si surface contamination). $\kappa R$ samples rest in an unclamped manner atop the alumina spacer and vacuum grease seals the test rig ground glass joint. 
To prevent atmospheric backflow into the $\kappa R$ fused silica test rig, cooled exit gas is bubbled through a gas bubbler filled with vacuum pump oil.

Controlled atmosphere $\kappa R$ gas mixtures are typically either bought outright or made inhouse via gas mixing. For example, in past SOFC cathode material $\kappa R$ studies, a $0.21 \mathrm{~atm}$ oxygen partial pressure gas has been obtained directly from a compressed air tank, while a $0.021 \mathrm{~atm}$ oxygen partial pressure mixture is obtained by combining $10 \mathrm{sccm}$ of mass flow controller (MC500SCCM-D-DB15K, Alicat Scientific; Tuscon, AZ) dispensed air and $90 \mathrm{sccm}$ of mass flow controller (MC-500SCCM-D-DB15K, Alicat Scientific; Tuscon, AZ) dispensed nitrogen. ${ }^{19,24}$ In all cases, the sample atmosphere is quickly switched between the two gas streams using a fourway ball value (SS-45YF4, Swagelok; Solon, OH).

\subsubsection{The Need for Controlled Atmosphere Gas Preheating}

Adequate gas preheating is essential for reliable $\kappa R$ measurements. In fact, inadequate gas preheating can lead to sample curvature fluctuations that overwhelm the mechano-electrochemical coupling response of a sample equilibrating to a new $\mathrm{pO}_{2}$; thereby making $k$ measurements through the use of Equations 4-5 impossible.

As shown in Figure 5, gas pre-heating problems often display themselves as 1) an initial curvature response that overshoots an equilibrium values and 2) a sample curvature response that occurs regardless of whether a mechano-chemically active layer is present, or not. These curvature fluctuations occur because inadequately pre-heated gas with a temperature different than that initially around the sample (which occurs as a result of the different thermal conductivities of the original and new gas mixtures) preferentially cools, or warms, one side of the sample (due to nonuniform gas currents within the sample chamber). In the case of switching between $100 \mathrm{sccm}$ of 
air (with a $25-725^{\circ} \mathrm{C}$ thermal conductivity between 26.18 and $\left.67.85 \mathrm{~mW} /(\mathrm{m} * \mathrm{~K})\right)^{43}$ and $100 \mathrm{sccm}$ of nitrogen (with a thermal conductivity between 25.8 and $67.7 \mathrm{~mW} /(\mathrm{m} * \mathrm{~K})$ from $\left.25-725^{\circ} \mathrm{C}\right),{ }^{44} \mathrm{a}$ thermocouple placed at the sample position can detect a temperature change of several degrees when the atmosphere is switched. However, when the gas-preheating spirals described in Section 3.2.1 are employed, no temperature changes are detected by a thermocouple at the sample location when the atmosphere is changed from nitrogen to air (at least not at temperatures $\leq 725^{\circ} \mathrm{C}$ and flow rates $\leq 500 \mathrm{sccm}$ ), and the observed curvature relaxations are similar in shape to those in Figure 1.

\section{$\underline{3.3 \text { Measurable } k \text { Values }}$}

The $k$ values that can be obtained from typical $\kappa R$ samples range from $2 \times 10^{-5}$ to $5 \times 10^{-10}$ $\mathrm{cm} / \mathrm{sec}$. The upper $k$ limit is set by the film thickness (or the particle thickness in the case of a porous film) and the reactor flush time $\left(\tau_{f}\right)$. This is because for a dense film:

$$
k_{i}=h_{f} / \tau_{i}
$$

where $\tau_{i}$ is the characteristic time for individual relaxation process $i$ in the film, and the other variables have their previously defined meanings. The error-free use of Equations 4 and 5 require that the reactor atmosphere be flushed "instantly" so that the observed relaxation corresponds solely to the response of the material (instead of the material responding much quicker than the reactor gas volume is exchanged, in which case the sample would act as a reactor flush time sensor). Mathematical analyses available in the literature have shown that, assuming the sample is surface controlled (i.e. $h_{f}$ or $P<<0.03 L_{c}$ ), $\tau_{f}$ needs to be less than 3 times that of the largest sample time constant $\tau_{i}$ to reliably determine $k$ using Equations 3 and $4 .{ }^{45}$ For a continuously 
stirred reactor, $\tau_{f}$ depends upon the reactor volume $\left(V_{r}\right)$ the gas flow rate $(\Phi)$ and the reactor temperature in Kelvin $\left(T_{r}\right)$ according to:

$$
\tau_{f}=\frac{V_{r} T_{S T P}}{\Phi T_{r}}
$$

where $T_{S T P}$ is $298 \mathrm{~K} .{ }^{45}$ Thus, a $10 \mathrm{~mL}$ reactor flushed with $100 \mathrm{sccm}$ of $600^{\circ} \mathrm{C}$ gas has a $\tau_{f}$ of 2.0 seconds, allowing Equations 3 and 4 to reliably measure $k<2 \times 10^{-5} \mathrm{~cm} / \mathrm{sec}$ values on $100 \mathrm{~nm}$ films.

As shown in Figure 6, flush time compromised $k$ 's can be identified experimentally using two methods (experimental identification of flush-time compromised $k$ values is especially important in those cases where $V_{r}$ is unknown, complicated gas flow patterns prevent the reactor being modeled as a continuously stirred reactor, and/or slow gas transport through the pores of a porous film are a potential cause for concern). The first method involves increasing the reactor gas flow rate by at least 3 times and determining whether $k$ changes. If it does not, the sample is not flush time limited. ${ }^{45}$ The second method involves analyzing the $k$ activation energy, since a true $k$ will behave in an Arrhenius manner (with an activation energy typically of at least a few tenths of an $\mathrm{eV}$ ), while a flush time compromised $k$ will remain essentially constant with temperature (with an apparent activation energy close to $0.07 \mathrm{eV}$ in accordance with Equation 12 for typical SOFC operating temperature ranges).

The lower $k$ limit is set by the temperature stability of the kSA MOS optics (which is controlled by the room's heating, ventilation, and air conditioning characteristics) and the patience of the system operator. For reference, since KR experiments need to be conducted for at least five times the largest sample $\tau_{i}$ to ensure reliable fitting of the measured KR curves, ${ }^{45}$ a $100 \mathrm{~nm}$ thick sample requiring a 24 hour curvature relaxation would have a $k$ of $5 \times 10^{-10} \mathrm{~cm} / \mathrm{sec}$. 


\section{$\underline{\text { 3.4 Materials Considerations }}$}

\subsubsection{Requisite Substrate Properties}

Single crystal wafers make the best substrates for $\kappa R$ experiment because 1) they typically have larger fracture stresses than polycrystalline substrates, 2) they cannot plastically deform via grain boundary sliding, 3) they can be oriented and cut to exhibit directionally independent elastic properties in the plane of the substrate, and 4) they can easily be polished to yield optically flat and reflective surfaces (which facilitates subsequent thin film deposition or laser array reflection). In addition, single crystal wafers can also be left unpolished on one side, which simplifies thin film curvature measurements by preventing two sets of laser array reflections (one set from the exposed thin film surface and one from the exposed substrate surface).

Ideally, substrate materials should be commercially available in widths that larger than the typical 3-5 mm laser beam array. One inch $(25.4 \mathrm{~mm})$ diameter wafers are widely available, but smaller diameter wafers may be utilized when pulse laser deposited thin film thickness uniformity is a concern. Substrate materials should also remain chemically inert over the entire temperature and $p_{\mathrm{O}_{2}}$ range of interest when in contact with the mechano-chemically active film, the process gas, and the sample carrier support tube (as shown in Figure 4, a spacer can be used at the end of the support tube to help prevent contamination of the substrate by the support tube). To ease interpretation of the film stress vs. temperature data, it is also a good idea to select substrate materials that remain single phase over the entire temperature and $p_{\mathrm{O}_{2}}$ range experienced by the sample. Since Equations 4 and 5 are derived using Hooke's Law, ${ }^{19,24}$ the substrate material should remain linear elastic during the course of the $\kappa R$ experiment. The substrate material should also be mechano-chemically inactive to ensure that oxygen vacancy concentration changes in the film are the only source of bilayer curvature relaxation. In this regard, substrate materials containing 
cations potentially existing in multiple oxidation states should be treated with extreme caution, since they have the potential to undergo internal, mechano-chemically-active oxygen exchange reactions such as those in Equation 1. Since $M_{S}$ values are needed to extract the film stress via Equation 6, the Young's Modulus and Poisson ratio of the substrate material should be known for the temperatures and $p_{\mathrm{O}_{2}}$ conditions of interest (As shown by Equations 4 and 5, neither $M_{S}$ or $M_{f}$ are needed if only a film $k$ is desired). Further, the substrate's biaxial modulus should be constant over the intended $p_{\mathrm{O}_{2}}$ step size to ensure that oxygen vacancy concentration changes in the film are the only source of bilayer curvature relaxation. Lastly, knowledge of the substrate thermal expansion properties can be helpful in understanding the observed equilibrium bilayer curvature vs. temperature behavior.

Based on these requirements, corundum $\left(\alpha-\mathrm{Al}_{2} \mathrm{O}_{3}\right)$, spinel $\left(\mathrm{MgAl}_{2} \mathrm{O}_{4}\right)$, and cubic YSZ $\left(\left(\mathrm{Y}_{2} \mathrm{O}_{3}\right)_{\mathrm{x}}\left(\mathrm{ZrO}_{2}\right)_{1-\mathrm{x}}\right.$ where $\mathrm{x}>0.09$ to avoid the long-term destabilization of the cubic phase into the tetragonal phase $)^{46}$ are all recommended as substrate materials. All of these materials are commercially available in appropriately oriented, one inch diameter, single crystal wafers with either one side polished (useful for either thin or thick film $\kappa \mathrm{R}$ experiments) or two side polished (useful only for thick film $\kappa \mathrm{R}$ experiments) configurations from suppliers such as Crystec, $\mathrm{GmbH}$ (Berlin, Germany), Marketech (Port Townsend, WA, USA), MTI Corp. (Richmond, CA, USA) or University Wafer (Boston, MA, USA). All of these materials have high chemical stabilities ${ }^{47,48}$ and high melting points $\left(>2000^{\circ} \mathrm{C}\right)^{46,49}$ that limit chemical reactions or interdiffusion with many film materials (if film-substrate chemical interactions do occur, chemical barrier layers of cerium oxide or other materials can be utilized). All of these materials are single phase solids from 25$2000^{\circ} \mathrm{C},{ }^{46,49}$ all of them are mechano-chemically inactive, ${ }^{50-53}$ and all of them have high $25-800^{\circ} \mathrm{C}$ single-crystal yield stresses greater than $400 \mathrm{MPa} .{ }^{54-56}$ In addition, both polycrystalline and single 
crystal elastic property data from $25-1000^{\circ} \mathrm{C}$ in air exists for corundum, ${ }^{57,58}$ spinel, ${ }^{59,60}$ and cubic YSZ. ${ }^{61-64}$ Further, literature studies suggest that the $25-1000^{\circ} \mathrm{C}$ majority defect concentrations in bulk corundum, ${ }^{65-67}$ spinel, ${ }^{51,68}$ and cubic YSZ are identical in air and hydrogen, with the result that their elastic constants in air and hydrogen only differ by a few percent ${ }^{61,64,65}$ (the fact that these elastic constants vary so little over the $>20$ orders of magnitude $p_{O_{2}}$ difference between air and hydrogen suggests they will be constant over the $\leq 1$ order of magnitude $p_{O_{2}}$ difference used in the typical $\kappa \mathrm{R}$ experiment). Lastly, temperature-dependent single-crystal thermal expansion data in air for corundum, ${ }^{69}$ spinel, ${ }^{69}$ and cubic $\mathrm{YSZ}^{63}$ is also available in the literature.

Regardless of the substrate material, all $\kappa \mathrm{R}$ wafers should be annealed at high temperature prior to use, so that residual stresses within the wafers may be removed. If this is not done, the relaxation of these residual stresses during a $\kappa \mathrm{R}$ experiment may cause wild bilayer-curvature vs. temperature behavior and/or prevent long-term, isothermal equilibrium curvature values from being achieved. The success of a particular substrate annealing schedule can be evaluated by measuring the curvature changes of bare, unclamped wafers as a function of temperature (which ideally should exhibit no curvature change vs. temperature). Annealing for 20 hours at $1450^{\circ} \mathrm{C}$ has been sufficient to relieve residual stress within $200 \mu \mathrm{m}$ thick YSZ wafers purchased from Crystec, MTI, and University Wafer.

\subsubsection{Requisite Film Properties}

In order to obtain $k$ from a $\kappa R$ experiment via Equations 4 or 5 , the film must 1) display first order (i.e. linear) oxygen surface exchange kinetics, 2) remain linear elastic during the oxygen exchange process, 3) have a biaxial elastic modulus that remain constant over the $p_{\mathrm{O}_{2}}$ step size, and 4) strain enough to produce measurable bilayer curvature changes. The first condition is 
usually met as long as the $p_{\mathrm{O}_{2}}$ difference between the initial and final gas is less than an order of magnitude. ${ }^{70,71}$ However, to ensure the film exhibits first order kinetics, it is advisable to use smaller step sizes and/or confirm that identical $k$ 's are obtained using various $p_{\mathrm{O}_{2}}$ step sizes (for instance oxidizing $p_{\mathrm{O}_{2}} /$ reducing $p_{\mathrm{O}_{2}}$ ratios of 2,5 or 10 ). The second condition is met by analyzing materials below their yield stress. The small grain size and surface constraints present in thin film geometries are beneficial in that they often raise the yield stress above that observed in bulk materials. ${ }^{72}$ However, ferroelastic phase transitions, high-temperature grain boundary sliding, and other film stress relaxation mechanisms that invalidate the use of Equations 4 and 5 may occur for some film materials under some conditions. Therefore, before extracting oxygen surface exchange coefficients from $\kappa \mathrm{R}$ data, bilayer linear elasticity should always be confirmed by ensuring that reproducible and time-independent equilibrium stresses are achieved with multiple $p_{\mathrm{O}_{2}}$ switching events (as shown in Figure 1a). Attempts to detect the onset of yielding should also made by searching for slope changes in equilibrium film stress vs. temperature plots and/or a sudden deviation from the equilibrium film stresses predicted via literature CTE and elastic property data, as observed in Yang and Nicholas. ${ }^{73}$ It is important to note that $\kappa R$ measurements may still be possible on materials which have yielded, so as long as $p_{\mathrm{O}_{2}}$ switching results in stresses that are less than or equal to the previously achieved maximum stress (many mechano-chemically active materials behave in a linear elastic manner as they are unloaded and then reloaded to the previously achieved maximum stress ${ }^{74}$ ). The third condition is also met by keeping the $p_{O_{2}}$ step size small. Thankfully, the $25-800^{\circ} \mathrm{C}$ biaxial moduli of most mechano-chemically active materials are essentially constant for a $p_{O_{2}}$ step size of $10 .{ }^{61,64,75,76}$ As evidenced from Equations 4- 6, one of the beauties of the $\kappa R$ technique is that film elastic constant values are not required to obtain either the oxygen surface exchange coefficient or the film stress. The fourth condition is met by studying 
film materials with a high chemical expansion coefficient, $\alpha_{c}$ (materials with a $\alpha_{c}$ greater than 0.01 , such as the high performance oxygen exchange materials in Table 1, typically work well), utilizing a sensitive curvature measurement setup (such as that described in Section 3.12), and depositing films that are both thin enough to ensure a roughly constant stress through the thickness of the film and thick enough to produce detectable curvature changes with $p_{\mathrm{O}_{2}}$ switching.

\section{$\underline{3.5 \text { Bilayer Geometry Considerations }}$}

The bilayer curvature changes expected for a given temperature or $p_{O_{2}}$ change can be calculated from known solutions in the literature, ${ }^{36,77}$ provided the bilayer geometry, the necessary film, and the necessary substrate materials properties (elastic and thermo-chemical expansion coefficients) are specified (see https://www.egr.msu.edu/nicholasgroup/ or Nicholas ${ }^{33}$ for MatLab code providing film stress vs. temperature predictions). Larger $h_{f}: h_{S}$ ratios allow the film to "tug" more on the underlying substrate (giving larger equilibrium curvature differences for a given $p_{\mathrm{O}_{2}}$ step size), while smaller $h_{f}: h_{S}$ ratios collapse Equations 7-9 to Stoney's Equation (Equation 6) and allow the film stress to be calculated without knowledge of the film elastic properties. Calculations made using available literature solutions ${ }^{36,77}$ (and subsequently corroborated by experiments) ${ }^{19,24,78}$ have shown that (for typical mechano-chemical film and inert substrate materials combinations) films $\sim 100 \mathrm{~nm}$ to $\sim 5 \mu \mathrm{m}$ in thickness on $200 \mu \mathrm{m}$ thick substrates give well-resolved bilayer curvature changes when a 1 order of magnitude $p_{\mathrm{O}_{2}}$ step size is used. As discussed in Section 2.2, the small $h_{f}: h_{S}$ ratios of these samples also collapse Equations 7-9 to Stoney's Equation (Equation 6) without much error; eliminating large through-film-thickness stress gradients that could complicate $\kappa \mathrm{R}$ fitting by invalidating the use of Equations 4 and 5 . 
Although not yet experimentally verified, calculations made using available literature solutions $^{36,77}$ suggest that well-resolved bilayer curvature changes may be possible for samples with films as thin as $\sim 10 \mathrm{~nm}$ when testing film materials with large chemical expansion coefficients (such as those in Table 1), utilizing substrates $\sim 150 \mu \mathrm{m}$ thick (wafers much thinner than this will likely be too fragile for handling and are not commercially available), and/or increasing the $p_{\mathrm{O}_{2}}$ step size (ensuring, of course, that the surface exchange process remains linear and the film and substrate elastic constants remain constant by checking that the same $k$ is obtained for a variety of $p_{\mathrm{O}_{2}}$ step sizes). $\kappa \mathrm{R}$ experiments utilizing Equations 4 and 5 should also be possible for films thicker than $5 \mu \mathrm{m}$, provided that 1) the $h_{f}: h_{S}$ ratio is kept below $\sim 40$ and 2) the dense film thickness or porous film particle size (not grain size) is less than $1 / 100^{\text {th }}$ of the characteristic thickness defined in Equation 3. Comparison with the characteristic thickness (which is available in the literature for many materials) ${ }^{10}$ ensures that the film's electrochemical response is complete surface controlled (if the film is truly surface-controlled, $k$ should remain constant as the film thickness is varied, all else being equal).

In all cases, the diameter of the bilayer should be much larger than the film thickness to allow edge effects to be ignored. As discussed in Freund and Suresh, ${ }^{36}$ edge effects typically only alter the stress state of material within $\sim 50$ film thicknesses of an edge, suggesting that $98 \%$ and $99.996 \%$ of a $5 \mu \mathrm{m}$ and $100 \mathrm{~nm}$ thick film, respectively, on a $25.4 \mathrm{~mm}$ wide substrate experience the thickness-averaged small-strain stress states predicted by Equations 6-9. That being said, a combination of large films strains (typically greater than a few tenths of a percent), large substrate diameter to substrate thickness ratios, and/or large film strains may invalidate the assumptions of linear elasticity and spherical bilayer curvature used to derive Equations 6-9. ${ }^{36}$ Therefore, Chapter 2 of Freund and Suresh should be consulted to identify sample geometries that will ensure the 
bilayers remain in the linear elastic regime, and substrates with smaller substrate diameter to substrate thickness ratios should be utilized if needed. In all cases, circular substrates are recommended to avoid the complicated stress states that may exist near sharp corners.

\subsection{System Costs}

An itemized $\kappa \mathrm{R}$ system parts list, showing that the total cost for a full $\kappa \mathrm{R}$ setup is around $\$ 90 \mathrm{k}$, is provided in Table 2 . Sample fabrication costs such as the $\sim \$ 100$ for each single crystal substrate, film deposition costs, etc. are not included in Table 2. Table 3 shows that the costs for a $\kappa \mathrm{R}$ setup compare favorably with other oxygen surface exchange measurement techniques.

The $\kappa \mathrm{R}$ setup cost in Table 2 are calculated assuming that four mass flow controllers (at $\$ 4950$ each) are used to produce two $\kappa \mathrm{R}$ gas mixtures (each with a different $p_{O_{2}}, p_{O_{2}}=0.21$ and 0.021, for instance) from two unmixed gas tanks (one nitrogen tank and one air tank, for instance). If only a few $\kappa$ R experiments are to be conducted, cost savings may be realized by only purchasing two mass flow controllers and ordering premixed gases (each with a different oxygen partial pressure) directly from a supplier. For tests on oxygen exchange materials that operate in air, cost savings may also be realized by replacing stainless steel tubing with plastic tubing and replacing stainless steel fittings with brass fittings. However, due to the oxygen permeability of most plastics and the chemical reactivity of brass, stainless steel tubing and fittings are recommended when using low $p_{O_{2}}$ or reactive gas mixtures.

\subsection{Comparison to Alternative Techniques}

As shown in Table 3, the $\kappa \mathrm{R}$ technique is presently one of the cheapest electrode-free $k$ measurement techniques. Electrode-free $k$ measurement techniques are needed because the high 
surface area, closely-spaced interdigitated electrodes required to measure films with low electrical conductivity can lead to 1 ) inadvertent strain engineering of the film $c_{v}$ and $k$ via electrode-film CTE mismatch induced strain and the operation of mechano-chemically active reactions such as Equation 1, ${ }^{20,23}$ and 2) artificial $k$ enhancement caused by electrode-catalyzed oxygen incorporation at the film-electrode-gas triple phase boundary ${ }^{79}$ (in films with high electrical conductivity, electrode use is not a problem because the electrodes can be placed far apart and made to cover only a small fraction of the exposed film surface). The $\kappa \mathrm{R}$ technique is also the only technique presently able to simultaneously measure a material's stress state and oxygen surface exchange coefficient. Further, the $\kappa \mathrm{R}$ technique has the added convenience of allowing in situ or in operando measurements.

The $\kappa \mathrm{R}$ technique is limited by the fact that, like the Electrical Conductivity Relaxation (ECR), Coulombic Titration, Electrical Titration, Gravimetric Relaxation, Optical Relaxation, Atmospheric Relaxation, and Strain Relaxation techniques, $k$ values can only be measured on materials that exhibit a change in their bulk oxygen vacancy concertation with $p_{\mathrm{O}_{2}}$ at the temperatures of interest (thankfully most high performance oxygen exchange materials are not in their Brouwer diagram electrolytic domains and therefore exhibit a change in oxygen content with a change in $p_{\mathrm{O}_{2}}$ ). Like the ECR technique, gas flushing and gas preheating problems typically set an upper limit on the measurable $\mathrm{k}$ values of $\sim 2 \times 10^{-5} \mathrm{~cm} / \mathrm{sec}$ (higher $k$ values can be inferred, to some extent, by extrapolating low-temperature data). The $\kappa \mathrm{R}$ technique is also limited by the fact that it requires the film to be mechano-chemically active (i.e. it must exhibit a lattice strain when it changes its oxygen concentration). Thankfully, most materials exhibit a lattice distortion when oxygen is removed. The biggest limitations of the $\kappa \mathrm{R}$ technique are that the technique requires 1 ) that oxygen exchange be the only source of $\rho_{O_{2}}$-induced mechanical relaxation in the film, and 2) 
that the film remain well-bonded to the substrate. Thankfully, as discussed in Section 3.4.2 inelastic relaxation processes can be detected by monitoring the long-term equilibrium curvature, comparing the k's obtained from multiple relaxations under identical conditions, and searching for sudden kinks in equilibrium stress vs. temperature plots. Film delamination and/or cracking can also be detected by sudden kinks in equilibrium stress vs. temperature plots.

\subsection{Conclusions}

In conclusion, the curvature relaxation technique is a new, electrode-free method for simultaneously measuring a material's film stress and chemical oxygen surface exchange coefficient under in situ or in operando conditions. In its present form, it can be used on dense or

porous, thin or thick film materials, provided the $h_{f}: h_{S}$ ratio is low enough to allow application of Stoney's Equation, and the film thickness (in the case of dense films) or particle size (in the case of porous films) is much less than the material's characteristic thickness. It is presently among the cheapest electrode-free techniques for measuring oxygen surface exchange coefficients, and the only technique yielding simultaneous $k$ and stress data. Further, since most materials strain in response to a change in composition, the curvature relaxation technique promises to be an important tool in establishing the links between mechanics and electrochemistry in a variety of solid state battery, fuel cell, memristor, ion exchange, and catalytically-active materials. The technique will also provide instrumental in determining if it is possible to strain-engineer ionic transport properties.

\subsection{Acknowledgements}

This work was supported by National Science Foundation (NSF) award No. CBET-1254453. The author would like to thank Michigan State University glass blower Scott Bancroft for his 
contributions to the development of the controlled atmosphere test rig, and Mr. Yuxi Ma for assistance with the technical drawings. 
Table 1. Common Mechano-Chemically Active Oxygen Exchange Materials

\begin{tabular}{|c|c|c|}
\hline Material & $\begin{array}{c}\text { Measured } \\
\text { Temperature } \\
\left({ }^{\circ} \mathrm{C}\right)\end{array}$ & $\begin{array}{c}\text { Chemical Expansion } \\
\text { Coefficient, } \alpha_{c}\end{array}$ \\
\hline$C e_{0.9} G d_{0.1} O_{1.95-\delta}$ & $700-900$ & $0.14^{80,81} \dagger$ \\
\hline $\mathrm{CeO}_{2}$ & 800 & $0.10^{81,82}$ \\
\hline $\mathrm{La}_{0.3} \mathrm{Sr}_{0.7} \mathrm{FeO}_{3-\delta}$ & $650-875$ & $0.017-0.047^{83}$ \\
\hline$L a_{0.6} S_{0.4} \mathrm{Co}_{0.8} F e_{0.2} \mathrm{O}_{3-\delta}$ & $700-900$ & $0.031^{84,85}$ \\
\hline $\begin{array}{l}\mathrm{La}_{1-x} \mathrm{Sr}_{x} \mathrm{CoO}_{3-\delta} \\
0.2 \leq \mathrm{x} \leq 0.8\end{array}$ & $600-900$ & $0.023-0.024^{84,86}$ \\
\hline $\begin{array}{l}\mathrm{SrFe}_{1-x} \mathrm{Ti}_{x} \mathrm{O}_{3-\delta} \\
0.25 \leq \mathrm{x} \leq 0.7\end{array}$ & 23 & $0.03^{87}$ \\
\hline$B a_{0.6} \mathrm{Sr}_{0.4} \mathrm{Co}_{0.8} \mathrm{Fe}_{0.2} \mathrm{O}_{3-\delta}$ & $600-900$ & $0.026-0.016^{88}$ \\
\hline $\begin{array}{c}L a_{1-x} \mathrm{Sr}_{x} \mathrm{CrO}_{3-\delta} \\
0.16 \leq \mathrm{x} \leq 0.3\end{array}$ & 1000 & $0.024^{89}$ \\
\hline $\mathrm{LaMnO}_{3-\delta}$ & $600-1000$ & $0.024^{90}$ \\
\hline \multicolumn{3}{|c|}{$\begin{array}{c}\dagger \text { For } 0 \leq \delta \leq 0.05 \text {. Although nonlinear above } 0.05, \alpha_{c} \text { is } \\
\text { always } \sim \text { linear for } \Delta \delta \leq 0.0180\end{array}$} \\
\hline
\end{tabular}


Table 2. $\kappa R$ System Equipment and Vendor List

\begin{tabular}{|c|c|c|c|c|}
\hline $\begin{array}{c}\text { Component } \\
\text { (Total Cost) }\end{array}$ & Vendor & Item \# & Item Description & $\begin{array}{l}\text { Approx. } \\
\text { Item Cost }\end{array}$ \\
\hline \multirow{7}{*}{$\begin{array}{l}\text { Controlled } \\
\text { Atmosphere } \\
\text { Test Rig } \\
(\mathbf{\$ 1 1 6 3 )}\end{array}$} & \multirow{5}{*}{$\begin{array}{l}\text { Technical Glass } \\
\text { Products } \\
\text { (Painesville } \\
\text { Township, OH) }\end{array}$} & $20 \times 25$ & $\begin{array}{l}22 \mathrm{~mm} \text { ID-25 mm OD Fused Silica Tubing for Inner } \\
\text { Support Tube, } 5 \mathrm{~cm} \text { long }\end{array}$ & $\$ 32$ \\
\hline & & $27 \times 30$ & $\begin{array}{l}27 \mathrm{~mm} \text { ID-30 } \mathrm{mm} \text { OD Fused Silica Tubing for Outer } \\
\text { Support Tube, } 5 \mathrm{~cm} \text { long }\end{array}$ & $\$ 25$ \\
\hline & & $4 X 6.35$ & $\begin{array}{l}4 \mathrm{~mm} \text { ID-6.35 mm OD Fused Silica Tubing for } \\
\text { Outer Support Tube Gas Preheating, } 3 \mathrm{~m} \text { long }\end{array}$ & $\$ 50$ \\
\hline & & $1 \mathrm{X} 0.125$ & Three Fused Silica Windows & $\$ 16$ \\
\hline & & STJ34-45M & 34/45 Fused Silica Joint & $\$ 30$ \\
\hline & \begin{tabular}{|l|}
$\begin{array}{l}\text { Coorstek } \\
\text { (Golden, CO) }\end{array}$ \\
\end{tabular} & $65825-01.0000$ & $\begin{array}{l}19 \mathrm{~mm} \text { ID-25 mm OD 99.8\% Pure } \mathrm{Al}_{2} \mathrm{O}_{3} \text { Tube, } 25 \mathrm{~mm} \\
\text { long }\end{array}$ & $\$ 10$ \\
\hline & $\begin{array}{l}\text { Michigan State } \\
\text { Glassblower }\end{array}$ & Custom & $\begin{array}{l}\text { Controlled Atmosphere Test Rig Assembly Labor } \\
\text { Costs }\end{array}$ & $\$ 1000$ \\
\hline \multirow{10}{*}{$\begin{array}{l}\text { Controlled } \\
\text { Atmosphere } \\
\text { Test Rig } \\
\text { Holder } \\
(\mathbf{\$ 2 , 0 8 5 )}\end{array}$} & \multirow{2}{*}{$\begin{array}{l}\text { Edmund Optics } \\
\text { (Barrington, NJ) }\end{array}$} & NT66-430 & X-Translation Stage for Test Rig Alignment & $\$ 375$ \\
\hline & & NT66-430 & Y-Translation Stages for Test Rig Tube Alignment & $\$ 375$ \\
\hline & \multirow{4}{*}{$\begin{array}{l}\text { Newport Optics } \\
\text { (Irvine, CA) }\end{array}$} & GON65-L & Lower Goniometer for Test Rig Tube Alignment & $\$ 500$ \\
\hline & & GON65-U & Upper Goniometer for Test Rig Alignment & $\$ 500$ \\
\hline & & AJS100-0.5 & Goniometer High Precision Small Knob Adj. Screw & $\$ 25$ \\
\hline & & $\begin{array}{l}\text { AJS100-0.5H } \\
\text { KD.75 }\end{array}$ & $\begin{array}{l}\text { High Precision Hex Adjustment Screw, Large } \\
\text { Actuator Knob }\end{array}$ & $\$ 30$ \\
\hline & \multirow{3}{*}{$\begin{array}{l}\text { CVI Melles Griot } \\
\text { (Albuquerque, } \\
\text { NM) }\end{array}$} & 07-DUP-011 & Stable Rod Post with Removable Base & $\$ 80$ \\
\hline & & 07-DSQ-003 & 1/4-20 Standard Stable Rod Carrier & $\$ 65$ \\
\hline & & 07-TSR-204 & Short Right Angle Bracket with 1/4-20 Holes & $\$ 65$ \\
\hline & $\begin{array}{l}\text { Michigan State } \\
\text { Machine Shop }\end{array}$ & Custom & Controlled Atmosphere Test Rig Mounting Bracket & $\$ 70$ \\
\hline \multirow{8}{*}{$\begin{array}{l}\text { Optical Table } \\
\text { Components } \\
(\mathbf{\$ 2 , 2 2 5 )}\end{array}$} & \multirow{6}{*}{$\begin{array}{l}\text { Edmund Optics } \\
\text { (Barrington, NJ) }\end{array}$} & NT43-420-522 & $50 \mathrm{~cm} \mathrm{OD} \lambda / 20$ Flat Zerodur Mirror & $\$ 245$ \\
\hline & & NT58-671 & Right Angle Post Clamp for the Zerodur Mirror & $\$ 15$ \\
\hline & & NT59-002 & $45^{\circ}$ Mounting Adapter for the Zerodur Mirror & $\$ 30$ \\
\hline & & NT59-751 & Optical Post for the Zerodur Mirror & $\$ 10$ \\
\hline & & NT58-976 & Optical Post Holder for the Zerodur Mirror & $\$ 10$ \\
\hline & & NT66-427 & Translation Stage for the $45^{\circ}$ Mirror & $\$ 375$ \\
\hline & $\begin{array}{l}\text { Thor Labs } \\
\text { (Newton, NJ) } \\
\end{array}$ & PBI11112 & $100 \times 64 \times 6 \mathrm{~cm}$ Optical Breadboard & $\$ 1500$ \\
\hline & $\begin{array}{l}\text { Sorbothane } \\
(\text { Kent, } \mathrm{OH})\end{array}$ & 0510151-70-10 & Four 70 Durometer $6 \mathrm{~cm}$ OD Non-Skid Hemispheres & $\$ 40$ \\
\hline \multirow[t]{2}{*}{$\begin{array}{l}\text { Furnace } \\
(\mathbf{\$ 7 , 0 0 0 )}\end{array}$} & $\begin{array}{l}\text { Applied Test Sys. } \\
\text { (Butler, PA) }\end{array}$ & $3210-3.00-12-12$ & $\begin{array}{l}1200^{\circ} \mathrm{C} \text { Split Tube Furnace, Furnace Controller, RS- } \\
232 \text { Comm., and Over-Temperature Controller }\end{array}$ & $\$ 6,500$ \\
\hline & $\begin{array}{l}\text { McMaster-Carr } \\
\text { (Chicago, IL) }\end{array}$ & Various & $\begin{array}{l}\text { Unistrut Bars and Brackets for a Vertical Furnace } \\
\text { Support System }\end{array}$ & $\$ 500$ \\
\hline \multirow{6}{*}{$\begin{array}{l}\text { Gas Handling } \\
\text { Components } \\
\mathbf{( \$ 2 1 , 8 6 0 )}\end{array}$} & $\begin{array}{l}\text { Alicat } \\
\text { (Tucson, AZ) }\end{array}$ & $\begin{array}{l}\text { MC-500SCCM- } \\
\text { D-DB15K }\end{array}$ & $\begin{array}{l}\text { Four 0-500 sccm Mass Flow Controllers with Built } \\
\text { in Logic and Pre-calibrated Gas Selection }\end{array}$ & $\$ 19,800$ \\
\hline & \multirow{2}{*}{$\begin{array}{l}\text { Swagelok } \\
(\text { Solon, } \mathrm{OH})\end{array}$} & SS-45YF4 & Stainless Steel Four Way Ball Value & $\$ 430$ \\
\hline & & Various & Stainless Steel Tubing, Unions, Tees, Valves & $\$ 1000$ \\
\hline & $\begin{array}{l}\text { VWR } \\
\text { (Batavia, IL) }\end{array}$ & $55850-702$ & Two Stainless Steel Two Stage Regulators & $\$ 460$ \\
\hline & \multirow{2}{*}{$\begin{array}{l}\text { Airgas } \\
(\text { Lansing, MI) }\end{array}$} & 16071600 & Nitrogen, Research Grade, 99.9995\% Pure & $\$ 110$ \\
\hline & & 16049780 & Compressed Air, Chromatographic Grade & $\$ 60$ \\
\hline $\begin{array}{l}\text { MOS System } \\
(\mathbf{\$ 5 4 , 5 0 0 )}\end{array}$ & $\begin{array}{l}\text { k-Space } \\
\text { (Dexter, MI) }\end{array}$ & MOS & $\begin{array}{l}\text { Preassembled } 25 \mathrm{~mW}, 660 \mathrm{~nm} \text { Laser Multi-beam } \\
\text { Optical Stress Sensor with Control Software and On- } \\
\text { site Installation. No Automatic Mirror Tracking. }\end{array}$ & $\$ 54,500$ \\
\hline & & & (in 2012 U.S. Dollars): $\$ \mathbf{8 8 , 8 3 3}$ & \\
\hline
\end{tabular}


Table 3. A Comparison of Common Methods Used to Determine Oxygen Surface Exchange Coefficients

\begin{tabular}{|c|c|c|c|c|c|c|c|c|c|c|c|}
\hline Method & $\begin{array}{c}\text { Conductivity } \\
\text { Relaxation }\end{array}$ & Permeation & $\begin{array}{c}\text { Coulombic } \\
\text { Titration } \\
\end{array}$ & $\begin{array}{c}\text { Electrical } \\
\text { Titration } \\
\end{array}$ & $\begin{array}{l}\text { Curvature } \\
\text { Relaxation }\end{array}$ & $\begin{array}{c}\text { Impedance } \\
\text { Spectroscopy }\end{array}$ & $\begin{array}{c}\text { Gravimetric } \\
\text { Relaxation }\end{array}$ & $\begin{array}{c}\text { Optical } \\
\text { Relaxation }\end{array}$ & $\begin{array}{c}\text { Atmospheric } \\
\text { Relaxation }\end{array}$ & $\begin{array}{c}\text { Strain } \\
\text { Relaxation } \\
\end{array}$ & $\begin{array}{c}\text { Isotope Exchange } \\
\text { Depth Profiling } \\
\end{array}$ \\
\hline $\begin{array}{l}\text { Involves } \\
\text { measuring } \\
\text { the: }\end{array}$ & $\begin{array}{c}\text { electrical } \\
\text { conductivity } \\
\text { of a sample } \\
\text { equilibrating } \\
\text { to an } \\
\text { atmospheric } \\
\mathrm{pO}_{2} \text { change }\end{array}$ & $\begin{array}{l}\text { surface } \\
\text { dominated } \\
\text { through- } \\
\text { sample } \\
\text { surface } \\
\text { resistivity }\end{array}$ & $\begin{array}{c}\mathrm{pO}_{2} \text { around a } \\
\text { sample } \\
\text { equilibrating } \\
\text { to an } \\
\text { externally } \\
\text { imposed } \mathrm{pO}_{2} \\
\text { change }\end{array}$ & \begin{tabular}{|c}
$p \mathrm{O}_{2}$ \\
monitoring \\
around a \\
sample \\
equilibrating \\
to an \\
electrically \\
imposed $c_{V_{O}^{\circ}}$ \\
change
\end{tabular} & $\begin{array}{c}\text { curvature of } \\
\text { a bilayer } \\
\text { equilibrating } \\
\text { to an } \\
\text { atmospheric } \\
\mathrm{pO}_{2} \text { change }\end{array}$ & $\begin{array}{l}\text { electrochemic } \\
\text { al impedance } \\
\text { response of a } \\
\text { material, } \\
\text { possibly with } \\
\text { blocking } \\
\text { electrodes }\end{array}$ & $\begin{array}{c}\text { weight } \\
\text { change of a } \\
\text { sample } \\
\text { equilibrating } \\
\text { to an } \\
\text { atmospheric } \\
\mathrm{pO}_{2} \text { change }\end{array}$ & $\begin{array}{c}\text { optical } \\
\text { properties of } \\
\text { a sample } \\
\text { equilibrating } \\
\text { to an } \\
\text { atmospheric } \\
\mathrm{pO}_{2} \text { change }\end{array}$ & $\begin{array}{c}\text { gas } \\
\text { composition } \\
\text { around a } \\
\text { sample } \\
\text { equilibrating } \\
\text { to a change } \\
\text { in } \\
\text { atmospheric } \\
\mathrm{O}_{2} \text { isotope } \\
\text { ratios }\end{array}$ & $\begin{array}{c}\text { lattice } \\
\text { parameter of } \\
\text { a material } \\
\text { equilibrating } \\
\text { to an } \\
\text { atmospheric } \\
\mathrm{pO}_{2} \text { change }\end{array}$ & $\begin{array}{c}c_{O^{2-}}^{*} \text { depth profile } \\
\text { of a sample } \\
\text { equilibrating to a } \\
\text { change in } \\
\text { atmospheric } \mathrm{O}_{2} \\
\text { isotope ratios }\end{array}$ \\
\hline $\begin{array}{c}\text { Described } \\
\text { in Refs: }\end{array}$ & 91,92 & 93,94 & 95 & 96,97 & 19,24 & 98,99 & 100,101 & 102,103 & 104 & 105,106 & 107,108 \\
\hline $\begin{array}{c}\text { Measured k } \\
\text { variant }\end{array}$ & $\tilde{k}$ & $\tilde{k}$ & $\tilde{k}$ & $\tilde{k}$ & $\tilde{k}$ & $k_{O^{2-}}^{q}$ & $\tilde{k}$ & $\tilde{k}$ & $k_{O^{2-}}^{*}$ & $\tilde{k}$ & $k_{O^{2-}}^{*}$ \\
\hline $\begin{array}{l}\text { Obtains k } \\
\text { through }\end{array}$ & $\begin{array}{c}\text { Fick's } 2^{\text {nd }} \\
\text { Law solution } \\
\text { fitting }\end{array}$ & $\begin{array}{l}\text { Wagner } \\
\text { Equation }\end{array}$ & $\begin{array}{c}\text { Fick's } 2^{\text {nd }} \\
\text { Law solution } \\
\text { fitting }\end{array}$ & $\begin{array}{c}\text { Fick's } 2^{\text {nd }} \\
\text { Law solution } \\
\text { fitting }\end{array}$ & $\begin{array}{c}\text { Fick's } 2^{\text {nd }} \\
\text { Law solution } \\
\text { fitting }\end{array}$ & $\begin{array}{l}\text { Equivalent } \\
\text { Circuit } \\
\text { Modeling }\end{array}$ & $\begin{array}{c}\text { Fick's } 2^{\text {nd }} \\
\text { Law solution } \\
\text { fitting }\end{array}$ & $\begin{array}{c}\text { Fick's } 2^{\text {nd }} \\
\text { Law solution } \\
\text { fitting }\end{array}$ & $\begin{array}{c}\text { Fick's } 2^{\text {nd }} \\
\text { Law solution } \\
\text { fitting }\end{array}$ & $\begin{array}{c}\text { Fick's } 2^{\text {nd }} \\
\text { Law solution } \\
\text { fitting }\end{array}$ & $\begin{array}{c}\text { Fick's } 2^{\text {nd }} \text { Law } \\
\text { solution fitting } \\
\text { when } k \& D \text { are } \\
\text { co-limiting }\end{array}$ \\
\hline $\begin{array}{c}\text { Electrode- } \\
\text { free? }\end{array}$ & No & No & Yes & No & Yes & No & Yes & Yes & Yes & Yes & Yes \\
\hline $\begin{array}{c}\text { Suitable } \\
\text { for in situ, } \\
\text { bulk sample } \\
\text { or } \\
\text { thick film } \\
\text { analyses? }\end{array}$ & \multirow{2}{*}{$\begin{array}{c}\text { Yes, if the } \\
\text { material has a } \\
\text { change in } \\
\text { charged } \\
\text { defect } \\
\text { concentration }\end{array}$} & \multirow{2}{*}{$\begin{array}{c}\text { Yes below } \\
\sim 500^{\circ} \mathrm{C} \text {. } \\
\text { Glass seal } \\
\text { complications } \\
\text { typically } \\
\text { prevent } \\
\text { higher } \\
\text { temperature } \\
\text { experiments }\end{array}$} & \begin{tabular}{|c|} 
Yes, but \\
sealing \\
problems \\
often cause \\
complication \\
s above \\
$\sim 500^{\circ} \mathrm{C}$. \\
\end{tabular} & \begin{tabular}{|c|} 
Yes below \\
$\sim 500^{\circ} \mathrm{C}$. \\
Glass seal \\
complications \\
typically \\
prevent \\
higher \\
temperature \\
experiments \\
\end{tabular} & \multirow{2}{*}{$\begin{array}{l}\text { Yes, if the } \\
\text { material is } \\
\text { mechano- } \\
\text { chemically } \\
\text { active and it } \\
\text { behaves as a } \\
\text { linear elastic } \\
\text { solid }\end{array}$} & Yes & Yes & $\begin{array}{c}\text { Yes, if the } \\
\text { material has } \\
\text { optical } \\
\text { defects } \\
\text { influenced } \\
\text { by a change } \\
\text { in defect } \\
\text { concentratio } \\
n\end{array}$ & Yes & $\begin{array}{c}\text { Yes, if the } \\
\text { material is } \\
\text { mechano- } \\
\text { chemically } \\
\text { active and it } \\
\text { behaves as a } \\
\text { linear elastic } \\
\text { solid }\end{array}$ & \multirow{2}{*}{$\begin{array}{l}\text { No. } \\
\text { The need for high } \\
\text { vacuum conditions } \\
\text { during depth } \\
\text { profiling prevents } \\
\text { in situ } \\
\text { measurements }\end{array}$} \\
\hline $\begin{array}{c}\text { Suitable } \\
\text { for in situ, } \\
\text { thin film } \\
\text { analyses? }\end{array}$ & & & \begin{tabular}{|c|} 
No. \\
Voluminous \\
samples are \\
required to \\
noticeably \\
alter gas \\
composition
\end{tabular} & & & & $\begin{array}{c}\text { No. } \\
\text { Voluminous } \\
\text { samples are } \\
\text { required to } \\
\text { noticeably } \\
\text { alter weight }\end{array}$ & & \begin{tabular}{|c|} 
No. \\
Voluminous \\
samples are \\
required to \\
noticeably \\
alter gas \\
composition
\end{tabular} & & \\
\hline
\end{tabular}




\begin{tabular}{|c|c|c|c|c|c|c|c|c|c|c|c|}
\hline \begin{tabular}{|c|} 
Equipment \\
Costs
\end{tabular} & $\$$ & $\$$ & $\$$ & $\$$ & $\$ \$$ & $\$ \$$ & $\$ \$$ & $\$ \$$ & $\$ \$ \$$ & $\$ \$ \$$ & $\$ \$ \$ \$$ \\
\hline
\end{tabular}

$k_{O^{2-}}^{q}, k_{O^{2-}}^{*}$ and $\tilde{k}=$ electrically determined, tracer determined, and chemically determined (ambipolar) $k$, respectively. $c_{O^{2-}}=$ [total lattice oxygen], $c_{O^{-}}^{*}=$ [oxygen tracer], $c_{V_{O}^{*}}=$ [oxygen vacancy], $R_{S}=$ oxygen exchange surface resistance, $R=$ ideal gas constant, $T=$ temperature in kelvin, $F=$ Faraday's Constant, $I=$ current, and $V=$ voltage. Here, oxygen defects are assumed to be the only mobile ions. $\$$ denotes system costs less than $\sim \$ 50,000, \$ \$$ denotes system costs between $\sim \$ 50,000-\$ 100,000, \$ \$ \$$ denotes system costs between $\sim \$ 100,000-\$ 500,000$, and $\$ \$ \$$ denotes system costs above $\$ 500,000$. 
a)
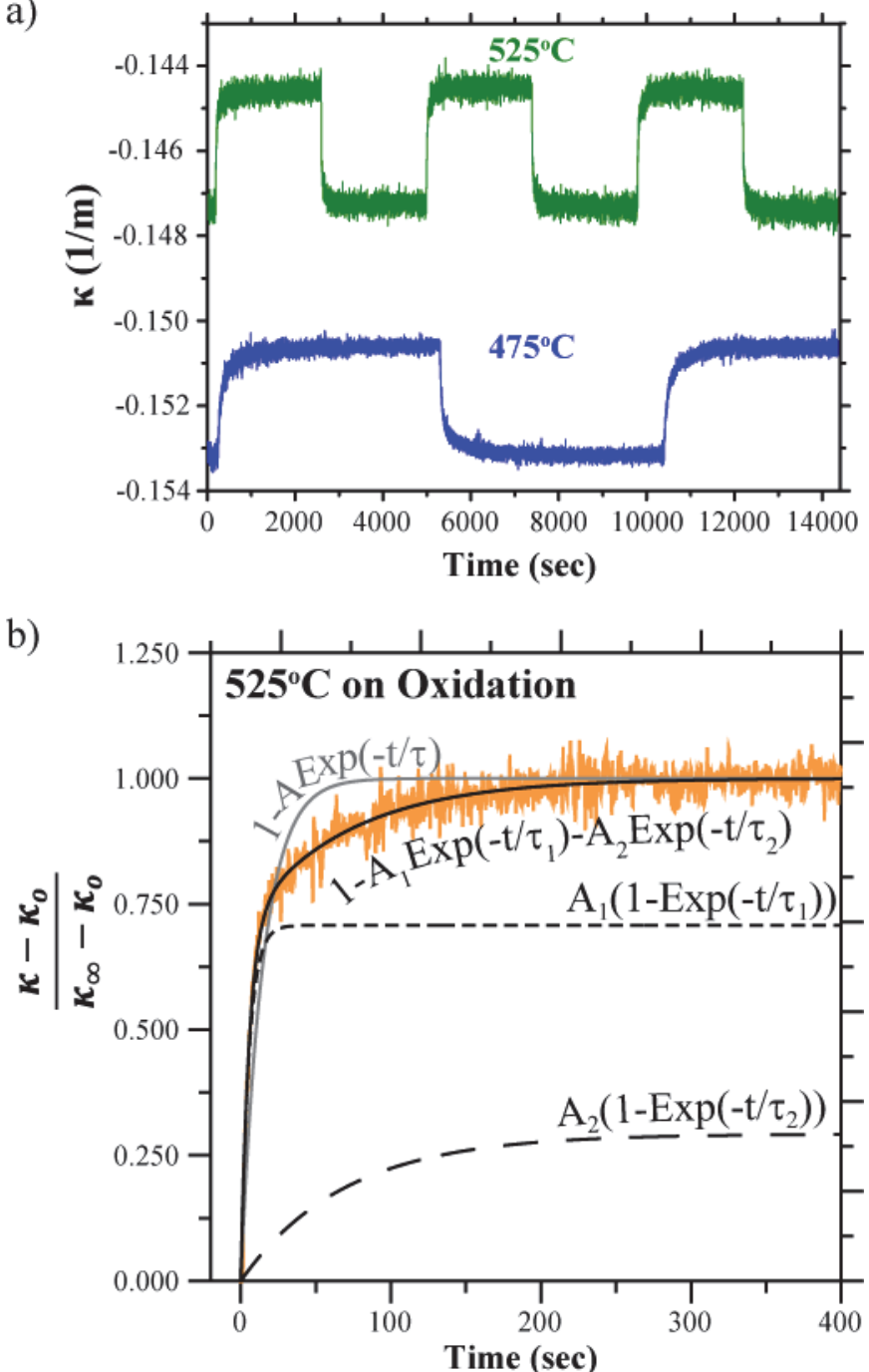

Figure 1. Representative (a) $\kappa R$ curves for a LSF64 film on a 100-oriented YSZ wafer with cycling between a $10 \%$ air - 90\% $\mathrm{N}_{2}$ mixture and 100\% air, from Yang ${ }^{78}$ and (b) normalized and fitted $\kappa R$ curve for a LSF64 film on a 100-oriented YSZ wafer with switching from a 10\% air - 90\% $\mathrm{N}_{2}$ mixture to $100 \%$ air showing that two oxygen exchange process are active, from Yang and Nicholas ${ }^{19}$ (reprinted with permission from Elsevier). 
a)

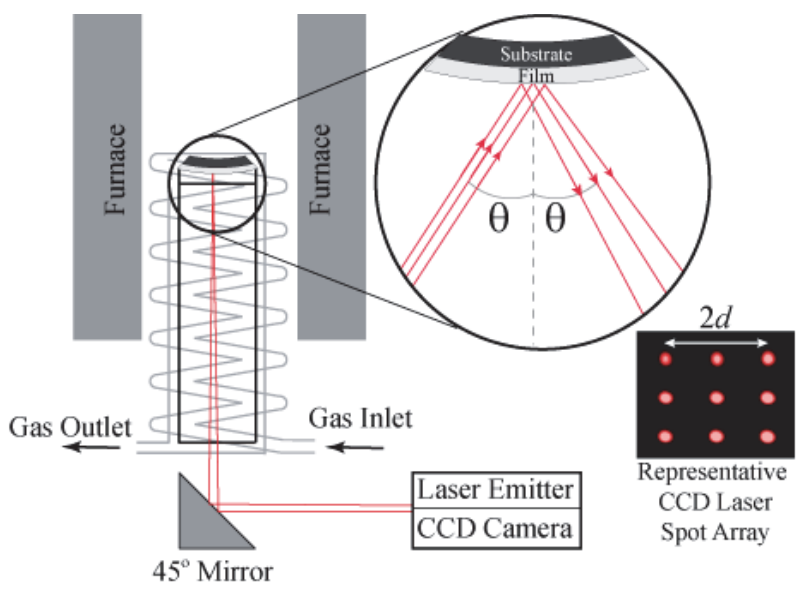

b)

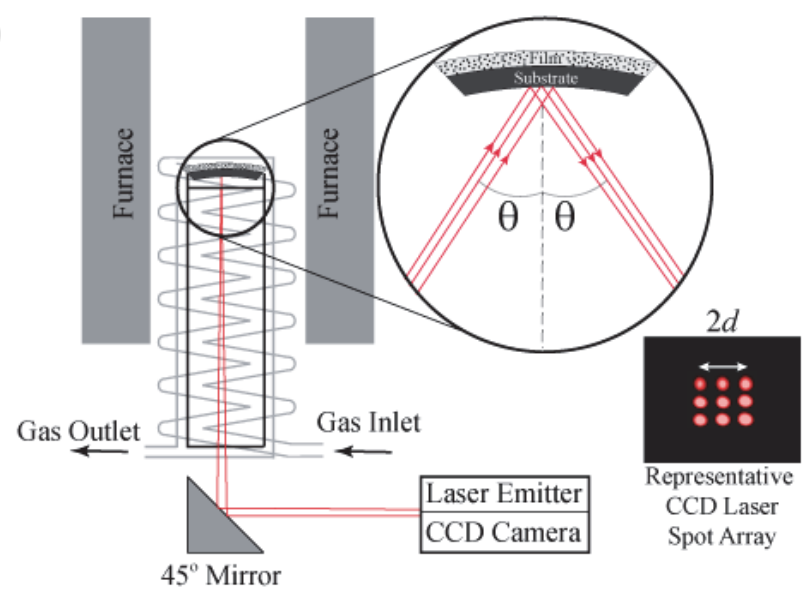

Figure 2. Schematics of the $k S A$ MOS Setup used to perform $\kappa R$ experiments for a) dense film/dense substrate bilayers, and b) porous film/dense substrate bilayers. Note that when studying dense films, as in part a), the kSA MOS laser beams are reflected off the film surface. In contrast, when studying porous films, as in part b) the kSA MOS laser beams are reflected off the substrate surface. These schematics are not drawn to scale and are drawn with arbitrary bilayer curvature. 

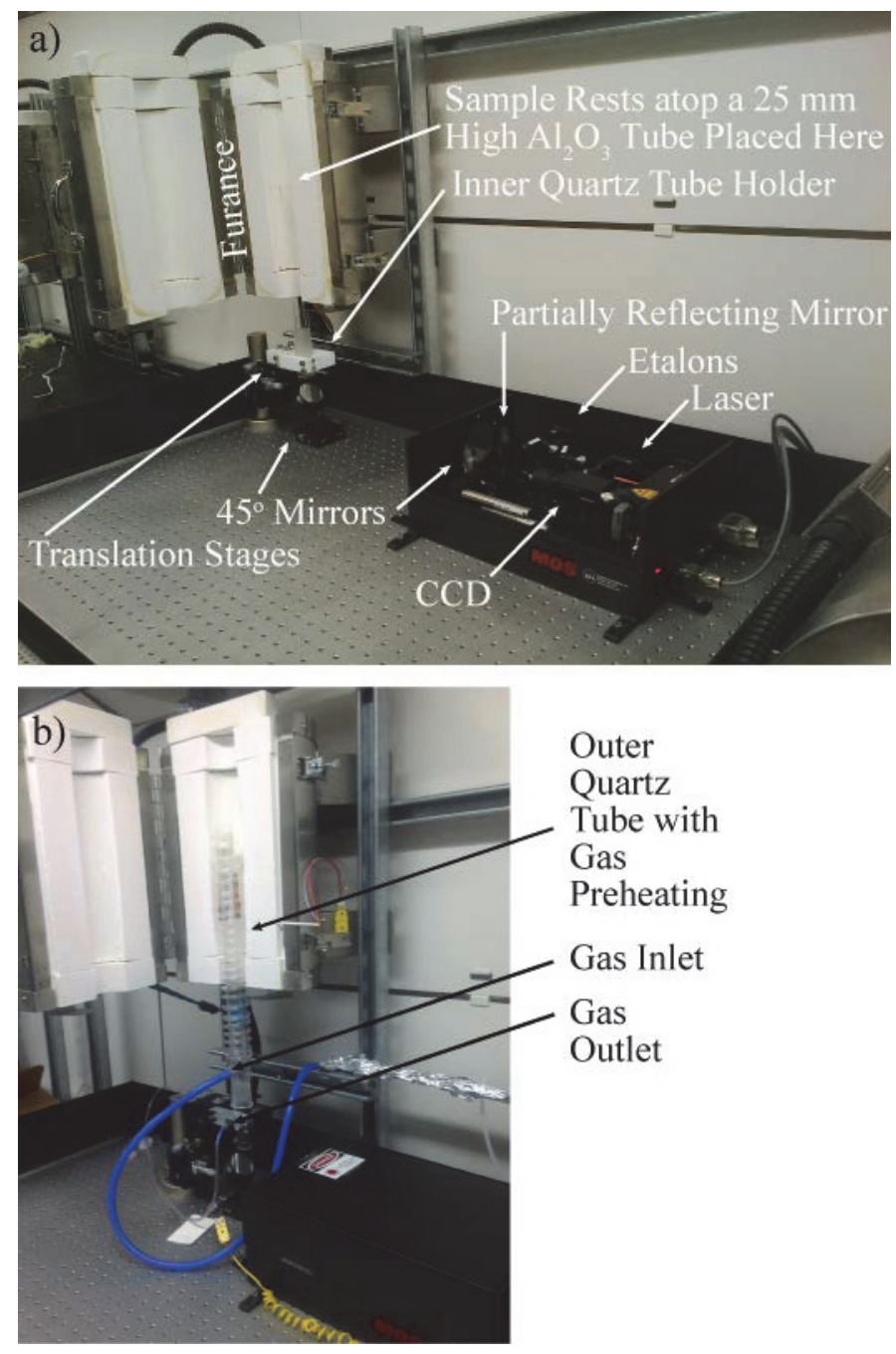

Figure 3. Pictures of the curvature relaxation setup a) with and b) without the outer quartz tube removed. 


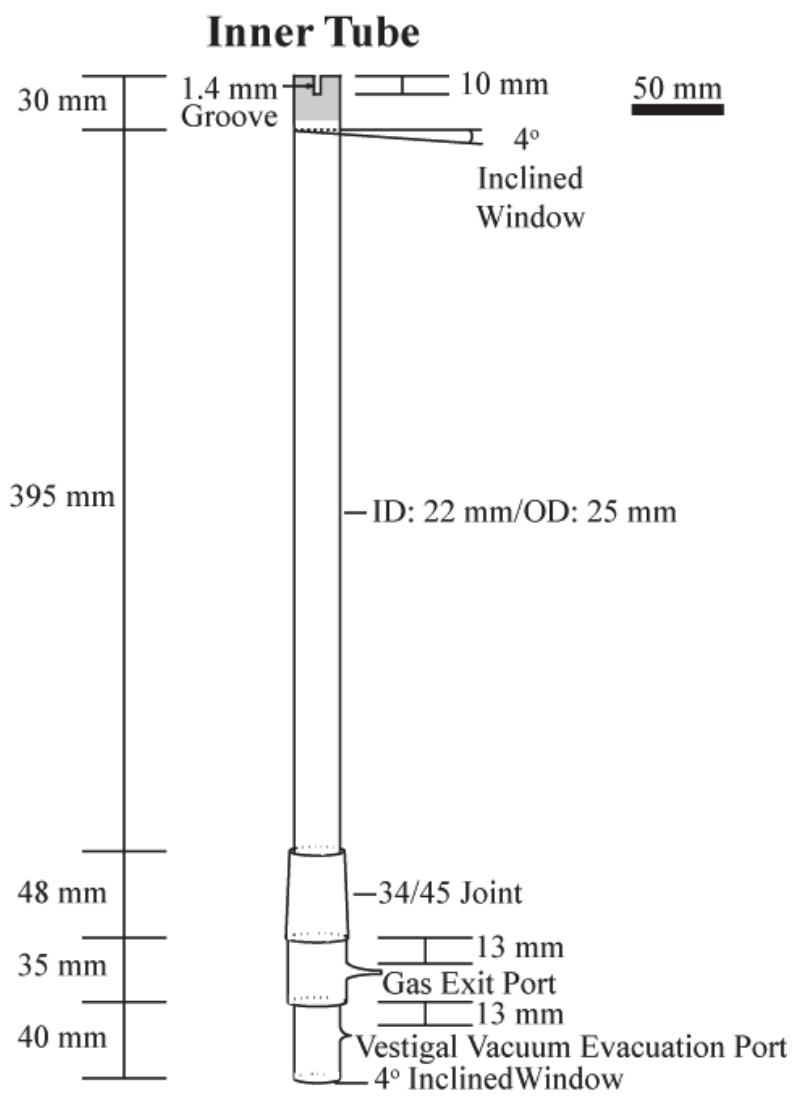

Outer Tube

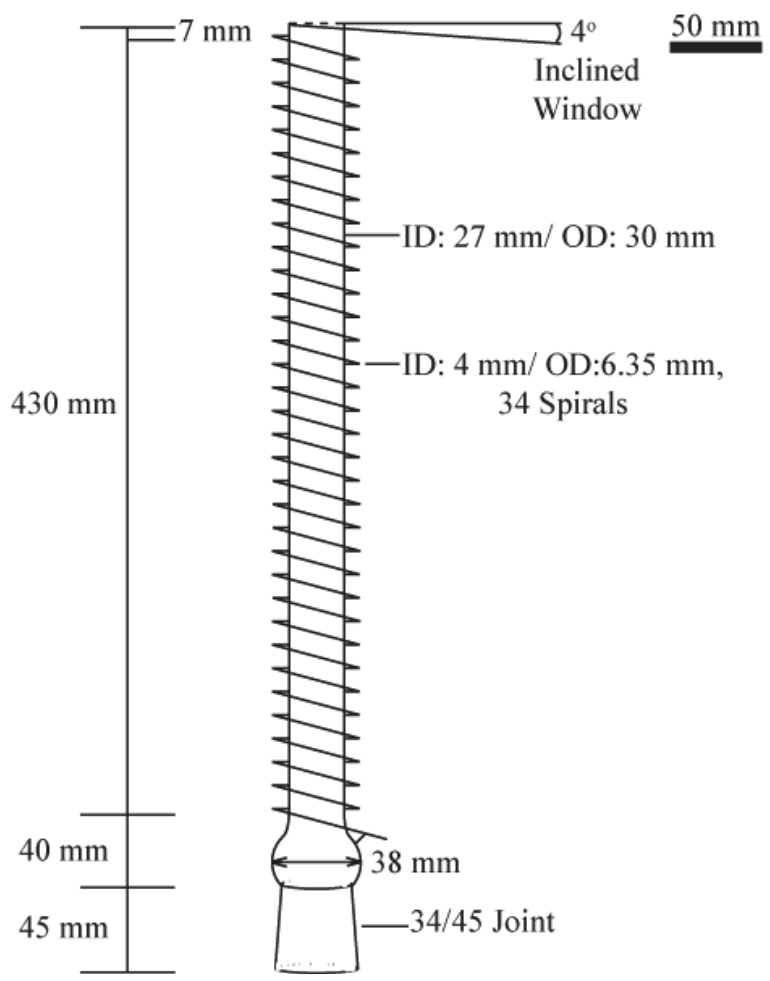

Figure 4. Schematic of the controlled atmosphere test rig. The shaded gray region represents the disposable alumina spacer used to support the sample. 


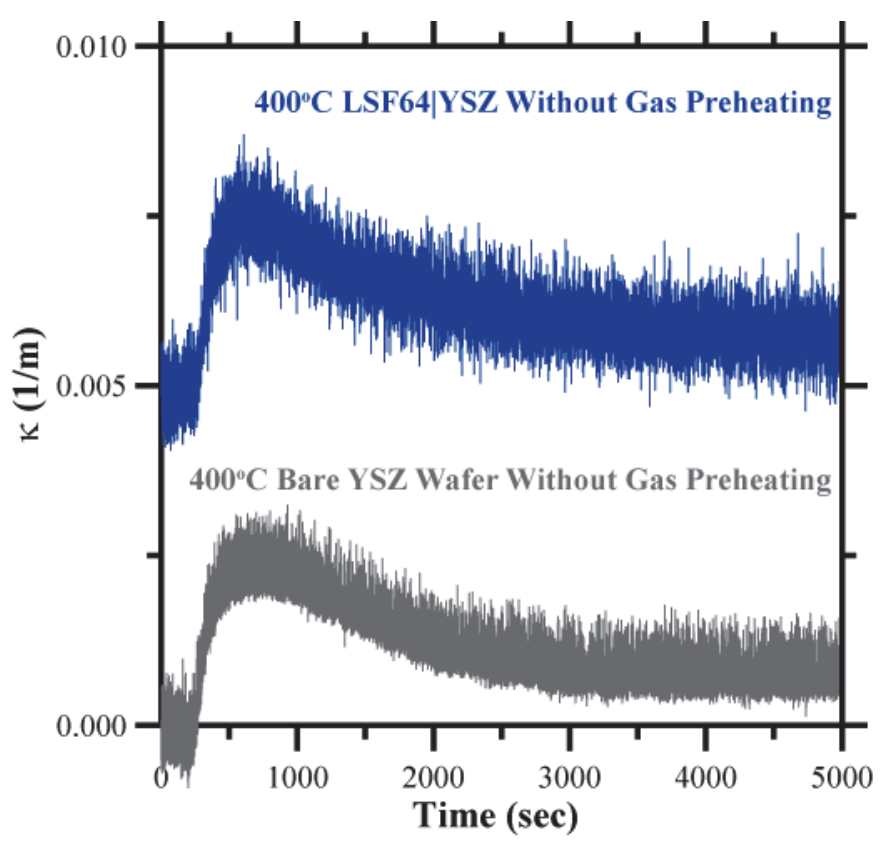

Figure 5. Sample curvature vs. time for a sputtered $100 \mathrm{~nm}$ thick LSF64 film on a $200 \mu \mathrm{m}$ thick 100-oriented YSZ substrate (top) and a bare $200 \mu \mathrm{m}$ thick 100-oriented YSZ substrate (bottom) when switching between $20 \mathrm{sccm}$ of $\mathrm{N}_{2}(0-300 \mathrm{sec})$ and $20 \mathrm{sccm}$ of air (300-5000 sec) without adequate gas preheating. See Figure 1 for the sample curvature vs. time behavior of a LSF64|YSZ sample with adequate gas preheating. 


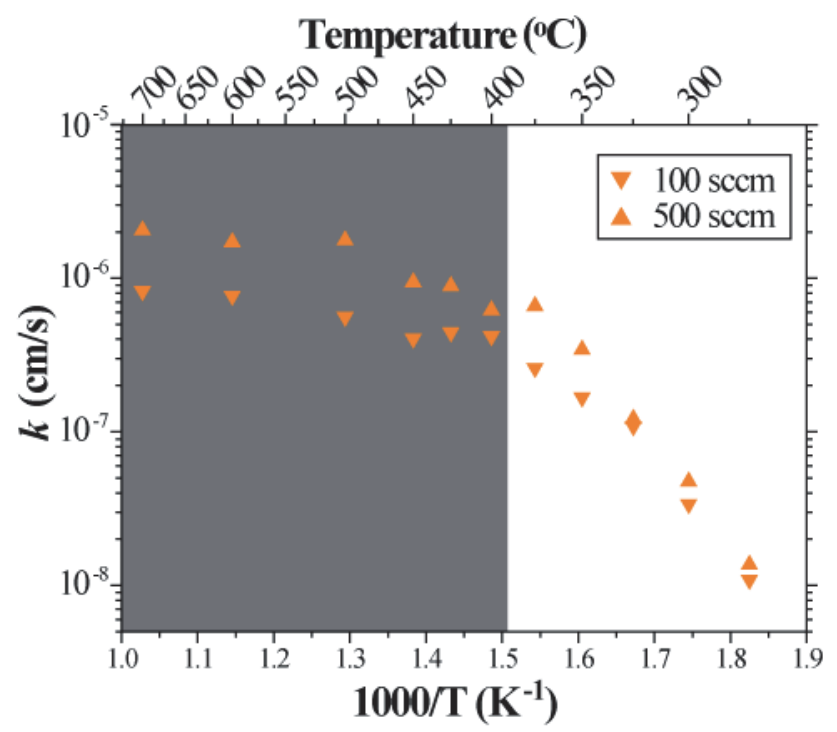

Figure 6. Real (white) and apparent (gray) oxygen surface exchange coefficients for a porous 4.7 $\mu \mathrm{m}$ LSF64 film on a $200 \mu \mathrm{m}$ thick 100-oriented YSZ substrate taken under various gas flow rates. As indicated by the change in slope of the $500 \mathrm{sccm}$ gas flow measurements, reliable $k$ measurements could not be obtained above $375^{\circ} \mathrm{C}$ due to reactor flush time limitations. The reliability of the 500 sccm measurements is confirmed by their low temperature agreement with the $100 \mathrm{sccm}$ measurements (reprinted with from Ref. ${ }^{24}$ with permission from the Electrochemical Society). 


\section{List of Symbols and Acronyms}

\begin{tabular}{|c|c|}
\hline$A_{i}$ & Area fraction \\
\hline$\alpha_{c}$ & Chemical expansion coefficient \\
\hline$\alpha_{T}$ & Coefficient of thermal expansion (CTE) \\
\hline$c_{v}$ & Instantaneous bulk oxygen vacancy concentration \\
\hline$c_{v o}$ & Initial $\mathrm{pO}_{2}$-equilibrated oxygen vacancy concentration \\
\hline$c_{v \infty}$ & New $p O_{2}$-equilibrated oxygen vacancy concentration \\
\hline$\delta$ & Instantaneous film oxygen nonstoichiometry \\
\hline$\delta_{0}$ & Initial film oxygen nonstoichiometry \\
\hline$\delta_{\infty}$ & New $p_{\mathrm{O}_{2}}$-equilibrated film oxygen nonstoichiometry \\
\hline$d$ & CCD-detected average inter-spot spacing \\
\hline$d_{o}$ & Spacing between the parallel laser beams striking the bilayer \\
\hline$D$ & Oxygen diffusion coefficient \\
\hline ECR & Electrical conductivity relaxation \\
\hline$E_{S}$ & Substrate Young's modulus \\
\hline$F e_{F e}^{\bullet}$ & Iron-bound electron holes \\
\hline$h_{f}$ & Film thickness \\
\hline$h_{s}$ & Substrate thickness \\
\hline$\Phi$ & Gas flow rate \\
\hline$k$ & Surface exchange coefficient \\
\hline$\kappa$ & Instantaneous bilayer curvature \\
\hline$\kappa_{0}$ & Initial bilayer curvature \\
\hline$\kappa_{\infty}$ & New $p_{\mathrm{O}_{2}}$-equilibrated bilayer curvature \\
\hline
\end{tabular}




\begin{tabular}{|c|c|}
\hline$\kappa R$ & Curvature relaxation \\
\hline$\lambda_{f}$ & Film stress \\
\hline $\bar{\lambda}$ & Thickness averaged film stress \\
\hline $\bar{\lambda}_{S t}$ & Thickness averaged film stress predicted from Stoney's Equation \\
\hline$L$ & Sample to CCD camera distance \\
\hline$L_{C}$ & Characteristic thickness \\
\hline LSF64 & $\mathrm{La}_{0.6} \mathrm{Sr}_{0.4} \mathrm{FeO}_{3-\delta}$ \\
\hline$M_{f}$ & Film biaxial modulus \\
\hline$M_{S}$ & Substrate biaxial modulus \\
\hline MIEC & Mixed Ionic Electronic Conducting \\
\hline MOS & Multi-beam Optical Sensor \\
\hline$O_{2(g)}$ & Oxygen gas \\
\hline$O_{o}^{x}$ & Lattice oxygen \\
\hline $\mathrm{pO}_{2}$ & Oxygen partial pressure \\
\hline$P$ & Particle size \\
\hline$R_{S}$ & Intrinsic oxygen surface exchange resistance \\
\hline$\sigma_{V_{o}^{*}}$ & Oxygen vacancy ionic conductivity \\
\hline $\mathrm{sccm}$ & Standard Cubic Centimeters per Minute (i.e. $\mathrm{mL} / \mathrm{min}$ ) \\
\hline SOFC & Solid Oxide Fuel Cell \\
\hline$S_{V}$ & Specific pore surface area \\
\hline$\theta$ & MOS laser beam array angle of reflection \\
\hline$\tau_{i}$ & Time constant \\
\hline$t$ & Time \\
\hline
\end{tabular}




$\begin{array}{ll}T & \text { Temperature } \\ T_{r} & \text { Reactor temperature in Kelvin } \\ v_{\mathrm{f}} & \text { Film Poisson's Ratio } \\ v_{\mathrm{S}} & \text { Substrate Poisson's Ratio } \\ V_{o}^{\bullet \bullet} & \text { Oxygen vacancy } \\ V_{r} & \text { Reactor volume } \\ V_{V} & \text { Volume fraction porosity } \\ \text { YSZ } & \text { Yttria Stabilized Zirconia } \\ z & \text { Film-normal distance from the substrate mid-plane }\end{array}$




\section{References}

[1] Z. Shao \& S. M. Haile. "A High-Perfromance Cathode for the Next Generation of Solid Oxide Fuel Cells." Nature 431: 170-173, (2004) http://dx.doi.org/10.1038/nature02863.

[2] B. C. H. Steele \& A. Heinzel. "Materials for Fuel-Cell Technologies." Nature 414: 345-352, (2001) http://dx.doi.org/10.1038/35104620.

[3] A. Atkinson, S. A. Barnett, R. J. Gorte, J. T. S. Irvine, A. J. McEvoy, M. B. Mogensen, S. Singhal \& J. Vohs. "Advanced Anodes for High Temperature Fuel Cells." Nat. Mater. 3: 17-27, (2004) http://dx.doi.org/10.1038/nmat1040.

[4] T. Z. Sholklapper, H. Kurokawa, C. P. Jacobson, S. J. Visco \& L. C. De Jonghe. "Nanostructured Solid Oxide Fuel Cell Electrodes." Nano Lett. 7 (7): 2136-2141, (2007) http://dx.doi.org/10.1021/n1071007i.

[5] J. D. Nicholas, L. Wang, A. V. Call \& S. A. Barnett. "Use of the Simple Infiltration Microstructure Polarization Loss Estimation (SIMPLE) Model to Predict the Measured Polarization Resistance of Infiltrated Nano-Composite Solid Oxide Fuel Cell Cathodes." Phys. Chem. Chem. Phys. 14 (44): 15379-15392, (2012) http://dx.doi.org/10.1039/C2CP43370B.

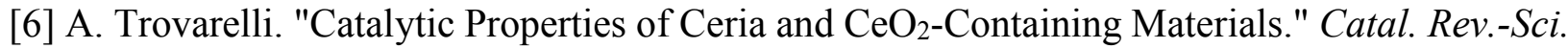
Eng. 38: 439-509, (1996) http://dx.doi.org/10.1080/01614949608006464.

[7] W. C. Chueh, C. Falter, M. Abbott, D. Scipio, P. Furler, S. M. Haile \& A. Steinfeld. "HighFlux Solar-Driven Thermochemical Dissociation of $\mathrm{CO}_{2}$ and $\mathrm{H}_{2} \mathrm{O}$ Using Nonstoichiometric Ceria." Science $330 \quad$ (6012): 1797-1801, (2010) http://dx.doi.org/10.1126/science.1197834.

[8] T. S. Stefanik \& H. L. Tuller. "Ceria-Based Gas Sensors." J. Eur. Ceram. Soc. 21 (10-11): 1967-1970, (2001) http://dx.doi.org/10.1016/s0955-2219(01)00152-2.

[9] A. Primo, T. Marino, A. Corma, R. Molinari \& H. Garcia. "Efficient Visible-Light Photocatalytic Water Splitting by Minute Amounts of Gold Supported on Nanoparticulate $\mathrm{CeO}_{2}$ Obtained by a Biopolymer Templating Method." J. Am. Chem. Soc. 133 (18): 69306933, (2011) http://dx.doi.org/10.1021/ja2011498.

[10] H. J. M. Bouwmeester \& A. J. Burggraff (1997). Dense Ceramic Membranes for Oxygen Separation. The CRC Handbook of Solid State Electrochemistry. P. J. Gellings \& H. J. M. Bouwmeester. New York, CRC Press: 481-554.

[11] P. N. Dyer, R. E. Richards, S. L. Russek \& D. M. Taylor. "Ion Transport Membrane Technology for Oxygen Separation and Syngas Production." Solid State Ionics 134 (1-2): 21-33, (2000) http://dx.doi.org/10.1016/S0167-2738(00)00710-4.

[12] J. Mizusaki, M. Yoshihiro, S. Yamauchi \& K. Fueki. "Nonstoichiometry and Defect Structure

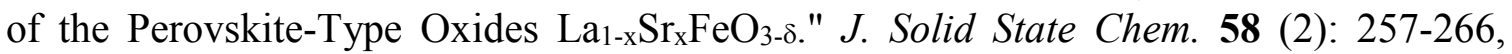
(1985) http://dx.doi.org/10.1016/0022-4596(85)90243-9.

[13] M. Sogaard, P. Vang Hendriksen \& M. Mogensen. "Oxygen Nonstoichiometry and Transport Properties of Strontium Substituted Lanthanum Ferrite." J. Solid State Chem. 180 (4): 1489-1503, (2007) http://dx.doi.org/10.1149/1.2789806.

[14] A. Karthikeyan \& S. Ramanathan. "Oxygen Surface Exchange Studies in Thin Film Gd-doped Ceria." Appl. Phys. Lett. 92 (24): 243109-243101 to 243109-243103, (2008) http://dx.doi.org/10.1063/1.2938028. 
[15] P. Ried, P. Holtappels, A. Wichser, A. Ulrich \& T. Graule. "Synthesis and Characterization of $\mathrm{La}_{0.6} \mathrm{Sr}_{0.4} \mathrm{Co}_{0.2} \mathrm{Fe}_{0.8} \mathrm{O}_{3-\mathrm{x}}$ and $\mathrm{Ba}_{0.5} \mathrm{Sr}_{0.5} \mathrm{Co}_{0.8} \mathrm{Fe}_{0.2} \mathrm{O}_{3-\mathrm{x} .}$." J. Electrochem. Soc. 155 (10): B1029-B1035, (2008) http://dx.doi.org/10.1149/1.2960873.

[16] P. Plonczak, M. Søgaard, A. Bieberle-Hütter, P. V. Hendriksen \& L. J. Gauckler. "Electrochemical Characterization of $\mathrm{La}_{0.58} \mathrm{Sr}_{0.4} \mathrm{Co}_{0.2} \mathrm{Fe}_{0.8} \mathrm{O}_{3-\delta}$ Thin Film Electrodes Prepared by Pulsed Laser Deposition." J. Electrochem. Soc. 159 (5): B471-B482, (2012) http://dx.doi.org/10.1149/2.043204jes.

[17] J. E. tenElshof, M. H. R. Lankhorst \& H. J. M. Bouwmeester. "Oxygen Exchange and Diffusion Coefficients of Strontium-doped Lanthanum Ferrites by Electrical Conductivity Relaxation." J. Electrochem. Soc. $144 \quad$ (3): 1060-1067, (1997) http://dx.doi.org/10.1149/1.1837531.

[18] M. Mosleh, M. Sogaard \& P. V. Hendriksen. "Kinetics and Mechanisms of Oxygen Surface Exchange on $\mathrm{La}_{0.6} \mathrm{Sr}_{0.4} \mathrm{FeO}_{3-\delta}$ Thin Films." J. Electrochem. Soc. 156 (4): B441-B457, (2009) http://dx.doi.org/10.1149/1.3062941.

[19] Q. Yang, T. E. Burye, R. R. Lunt \& J. D. Nicholas. "In situ Oxygen Surface Exchange Coefficient Measurements on Lanthanum Strontium Ferrite Thin Films via the Curvature Relaxation Method." Solid State Ionics 249-250: 123-128, (2013) http://dx.doi.org/10.1016/j.ssi.2013.07.025.

[20] M. Kubicek, Z. H. Cai, W. Ma, B. Yildiz, H. Hutter \& J. Fleig. "Tensile Lattice Strain Accelerates Oxygen Surface Exchange and Diffusion in $\mathrm{La}_{1-\mathrm{x}} \mathrm{Sr}_{\mathrm{x}} \mathrm{CoO}_{3-8}$ Thin Films." ACS Nano 7 (4): 3276-3286, (2013) http://dx.doi.org/10.1021/nn305987x.

[21] M. Chu, Y. K. Sun, U. Aghoram \& S. E. Thompson. "Strain: A Solution for Higher Carrier Mobility in Nanoscale MOSFETs." Ann. Rev. Mater. Res. 39: 203-229, (2009) http://dx.doi.org/10.1146/annurev-matsci-082908-145312.

[22] T. Mayeshiba \& D. Morgan. "Strain Effects on Oxygen Migration in Perovskites." Phys. Chem. Chem. Phys. 17 (4): 2715-2721, (2015) http://dx.doi.org/10.1039/c4cp05554c.

[23] R. A. De Souza, A. Ramadan \& S. Horner. "Modifying the Barriers for Oxygen-Vacancy Migration in Fluorite-structured $\mathrm{CeO}_{2}$ Electrolytes through Strain: A Computer Simulation Study." Energy Environ. $\quad$ Sci. $\quad 5 \quad$ (1): 5445-5453, $\quad$ (2012) http://dx.doi.org/10.1039/c2ee02508f.

[24] Q. Yang \& J. D. Nicholas. "Porous Thick Film Lanthanum Strontium Ferrite Stress and Oxygen Surface Exchange Bilayer Curvature Relaxation Measurements." J. Electrochem. Soc. 161 (11): F3025-F3031, (2014) http://dx.doi.org/10.1149/2.0051411jes.

[25] H. J. M. Bouwmeester, H. Kruidhof \& A. J. Burggraaf. "Importance of the Surface Exchange Kinetics as Rate Limiting Step in Oxygen Permeation through Mixed-Conducting Oxides." Solid State Ionics 72: 185-194, (1994) http://dx.doi.org/10.1016/0167-2738(94)90145-7.

[26] E. Fischer \& J. L. Hertz. "Measurability of the Diffusion and Surface Exchange Coefficients using Isotope Exchange with Thin Film and Traditional Samples." Solid State Ionics 218: 18-24, (2012) http://dx.doi.org/10.1016/j.ssi.2012.05.003.

[27] J. Crank (1975). The Mathematics of Diffusion. London, Oxford University Press.

[28] G. Kim, S. Wang, A. J. Jacobson \& C. L. Chen. "Measurement of Oxygen Transport Kinetics in Epitaxial $\mathrm{La}_{2} \mathrm{NiO}_{4+\delta}$ Thin Films by Electrical Conductivity Relaxation." Solid State Ionics 177 (17-18): 1461-1467, (2006) http://dx.doi.org/10.1016/j.ssi.2006.07.013.

[29] K. Kerman, C. Ko \& S. Ramanathan. "Orientation Dependent Oxygen Exchange Kinetics on Single Crystal $\mathrm{SrTiO}_{3}$ Surfaces." Phys. Chem. Chem. Phys. 14 (34): 11953-11960, (2012) http://dx.doi.org/10.1039/c2cp41918a. 
[30] C. H. Ko, A. Karthikeyan \& S. Ramanathan. "Studies on Oxygen Chemical Surface Exchange and Electrical Conduction in Thin Film Nanostructured Titania at High Temperatures and Varying Oxygen Pressure." J. Chem. Phys. 134 (1): 014704 -014701 to 014704 -014709, (2011) $\mathrm{http://dx.doi.org/10.1063/1.3524341.}$

[31] G. Kim, S. Wang, A. J. Jacobson, Z. Yuan, W. Donner, C. L. Chen, L. Reimus, P. Brodersen \& C. A. Mims. "Oxygen Exchange Kinetics of Epitaxial $\mathrm{PrBaCo}_{2} \mathrm{O}_{5+\mathrm{d}}$ Thin Films." Appl. Phys. Lett. $\mathbf{8 8} \quad$ (2): 024103-024101 to 024103-024103, (2006) http://dx.doi.org/10.1063/1.2163257.

[32] R. Ganeshananthan \& A. V. Virkar. "Measurement of Surface Exchange Coefficient on Porous $\mathrm{La}_{0.6} \mathrm{Sr}_{0.4} \mathrm{CoO}_{3-\delta}$ Samples by Conductivity Relaxation." J. Electrochem. Soc. 152 (8): A1620-A1628, (2005) http://dx.doi.org/10.1149/1.1940828.

[33] J. D. Nicholas (2016). In situ Wafer Curvature Relaxation Measurements to Determine Surface Exchange Coefficients and Thermo-Chemically Induced Stresses. Electro-ChemoMechanics of Solids. S. Bishop, D. Marriochelli, N. Perry, \& B. Sheldon. New York, Springer. In Press.

[34] R. A. Cox-Galhotra \& S. McIntosh. "Unreliability of Simultaneously Determining k-chem and D-chem via Conductivity Relaxation for Surface-Modified $\mathrm{La}_{0.6} \mathrm{Sr}_{0.4} \mathrm{Co}_{0.2} \mathrm{Fe}_{0.8} \mathrm{O}_{3-\delta .}$." Solid State Ionics $181 \quad$ (31-32): 1429-1436, $\quad$ (2010) http://dx.doi.org/10.1016/j.ssi.2010.08.006.

[35] M. F. Doerner, D. S. Gardner \& W. D. Nix. "Plastic Properties of Thin Films on Substrates as Measured by Submicron Indentation Hardness and Substrate Curvature Techniques." $J$. Mater. Res. 1 (6): 845-851, (1986) http://dx.doi.org/10.1557/jmr.1986.0845.

[36] L. B. Freund \& S. Suresh (2003). Thin Film Materials: Stress, Defect Formation and Surface Evolution. New York, NY, Cambridge University Press.

[37] G. Janssen, M. M. Abdalla, F. van Keulen, B. R. Pujada \& B. van Venrooy. "Celebrating the 100th Anniversary of the Stoney Equation for Film Stress: Developments from Polycrystalline Steel Strips to Single Crystal Silicon Wafers." Thin Solid Films 517 (6): 1858-1867, (2009) http://dx.doi.org/10.1016/j.tsf.2008.07.014.

[38] J. A. Floro, E. Chason \& S. R. Lee (1996). Real Time Measurement of Epilayer Strain using a Simplified Wafer Curvature Technique. Diagnostic Techniques for Semiconductor Materials Processing II. S. W. Pang, O. J. Glembocki, F. H. Pollak, F. G. Celii, \& C. M. SotomayorTorres. 406: 491-496.

[39] E. Chason, B. W. Sheldon, L. B. Freund, J. A. Floro \& S. J. Hearne. "Origin of Compressive Residual Stress in Polycrystalline Thin Films." Phys. Rev. Lett. 88 (15): 156103, (2002) http://dx.doi.org/10.1103/PhysRevLett.88.156103.

[40] B. W. Sheldon, S. Mandowara \& J. Rankin. "Grain Boundary Induced Compositional Stress in Nanocrystalline Ceria Films." Solid State Ionics 233 (0): 38-46, (2013) http://dx.doi.org/10.1016/j.ssi.2012.11.006.

[41] C. A. Klein. "How Accurate are Stoney's Equation and Recent Modifications." J. Appl. Phys. 88 (9): 5487-5489, (2000) http://dx.doi.org/10.1063/1.1313776.

[42] E. Bucher \& W. Sitte. "Long-term Stability of the Oxygen Exchange Properties of (La,Sr) ${ }_{z}(\mathrm{Co}, \mathrm{Fe}) \mathrm{O}_{3-\delta}$ in Dry and Wet Atmospheres." Solid State Ionics 192 (1): 480-482, (2011) http://dx.doi.org/10.1016/j.ssi.2010.01.006.

[43] K. Stephan \& A. Laesecke. "The Thermal Conductivity of Fluid Air." J. Phys. Chem. Ref. Data 14 (1): 227-234, (1985) http://dx.doi.org/10.1063/1.555749. 
[44] D. R. Linde, Ed. (2000). CRC Handbook of Chemistry and Physics. Boca Raton, FL, CRC Press.

[45] M. W. den Otter, H. J. M. Bouwmeester, B. A. Boukamp \& H. Verweij. "Reactor Flush Time Correction in Relaxation Experiments." J. Electrochem. Soc. 148 (2): J1-J6, (2001) http://dx.doi.org/10.1149/1.1337604.

[46] J. Chevalier, L. Gremillard, A. V. Virkar \& D. R. Clarke. "The Tetragonal-Monoclinic Transformation in Zirconia: Lessons Learned and Future Trends." J. Am. Cer. Soc. 92 (9): 1901-1920, (2009) http://dx.doi.org/10.1111/j.1551-2916.2009.03278.x.

[47] D. R. Gaskell (2008). Ellingham Diagrams. Introduction to the Thermodynamics of Materials. New York, Taylor \& Francis: 1-763.

[48] I. Barin (1995). Thermochemical Data of Pure Substances. New York, VCH.

[49] E. F. Osborn. "Subsolidus Reactions in Oxide Systems in the Presence of Water at High Pressures." J. Am. Cer. Soc. 36 (5): 147-151, (1953) http://dx.doi.org/10.1111/j.11512916.1953.tb12855.x.

[50] E. R. Dobrovinskaya, L. A. Lytvynov \& V. Pishchik (2009). Chapter 2: Properties of Sapphire. Sapphire: Material, Manufacturing, Applications. New York, Springer.

[51] E. Sonder. "Ionic Transference Numbers and Electrical Conduction in $\mathrm{MgAl}_{2} \mathrm{O}_{4}$ Spinel." $J$. Am. Cer. Soc. 66 (1): 50-53, (1983) http://dx.doi.org/10.1111/j.1151-2916.1983.tb09967.x.

[52] K. Sasaki \& J. Maier. "Re-analysis of Defect Equilibria and Transport Parameters in $\mathrm{Y}_{2} \mathrm{O}_{3}$ Stabilized $\mathrm{ZrO}_{2}$ using EPR and Optical Relaxation." Solid State Ionics 134 (3-4): 303-321, (2000) http://dx.doi.org/10.1016/S0167-2738(00)00766-9.

[53] J. H. Park \& R. N. Blumenthal. "Electronic Transport in 8 Mole Percent $\mathrm{Y}_{2} \mathrm{O}_{3}-\mathrm{ZrO}_{2}$." $J$. Electrochem. Soc. 136 (10): 2867-2876, (1989) http://dx.doi.org/10.1149/1.2096302.

[54] K. P. D. Lagerlof, A. H. Heuer, J. Castaing, J. P. Riviere \& T. E. Mitchell. "Slip and Twinning in Sapphire $\left(\alpha-\mathrm{Al}_{2} \mathrm{O}_{3}\right) . " \quad J . \quad A m . \quad$ Cer. Soc. 77 (2): 385-397, (1994) http://dx.doi.org/10.1111/j.1151-2916.1994.tb07006.x.

[55] T. E. Mitchell. "Dislocations and Mechanical Properties of $\mathrm{MgO}-\mathrm{Al}_{2} \mathrm{O}_{3}$ Spinel Single Crystals." J. Am. Cer. Soc. 82 (12): 3305-3316, (1999) http://dx.doi.org/10.1111/j.11512916.1999.tb02244.x.

[56] U. Messerschmidt, D. Baither, B. Baufeld \& M. Bartsch. "Plastic Deformation of Zirconia Single Crystals: A Review." Mat. Sci. Eng. A-Struct. 233 (1-2): 61-74, (1997) http://dx.doi.org/10.1016/s0921-5093(97)00050-6.

[57] S. V. Sinogeikin, D. L. Lakshtanov, J. D. Nicholas, J. M. Jackson \& J. D. Bass. "High Temperature Elasticity Measurements on Oxides by Brillouin Spectroscopy with Resistive and IR Laser Heating." J. Eur. Ceram. Soc. 25 (8): 1313-1324, (2005) http://dx.doi.org/10.1016/j.jeurceramsoc.2005.01.001

[58] R. G. Munro. "Evaluated Material Properties for a Sintered $\alpha$-Alumina." J. Am. Cer. Soc. 80 (8): 1919-1928, (1997) http://dx.doi.org/10.1111/j.1151-2916.1997.tb03074.x.

[59] I. Suzuki, I. Ohno \& O. L. Anderson. "Harmonic and Anharmonic Properties of Spinel $\mathrm{MgAl}_{2} \mathrm{O}_{4}$." Am. Miner. 85 (2): 304-311, (2000) http://dx.doi.org/10.2138/am-2000-2-307.

[60] C. Baudin, R. Martinez \& P. Pena. "High Temperature Mechanical Behavior of Stoichiometric Magnesium Spinel." J. Am. Cer. Soc. 78 (7): 1857-1862, (1995) http://dx.doi.org/10.1111/j.1151-2916.1995.tb08900.x.

[61] T. Kushi, K. Sato, A. Unemoto, S. Hashimoto, K. Amezawa \& T. Kawada. "Elastic Modulus and Internal Friction of SOFC Electrolytes at High Temperatures under Controlled 
Atmospheres." J. Power Sources $196 \quad$ (19): 7989-7993, (2011) http://dx.doi.org/10.1016/j.jpowsour.2011.05.040.

[62] S. Giraud \& J. Canel. "Young's Modulus of Some SOFCs Materials as a Function of Temperature." J. Eur. Ceram. Soc. $28 \quad$ (1): 77-83, (2008) http://dx.doi.org/10.1016/j.jeurceramsoc.2007.05.009.

[63] P. J. Botha, J. C. H. Chiang, J. D. Comins, P. M. Mjwara \& P. E. Ngoepe. "Behavior of Elastic Constants, Refractive Index, and Lattice Parameter of Cubic Zirconia at High Temperatures." J. Appl. Phys. $73 \quad$ (11): 7268-7274, (1993) http://dx.doi.org/10.1063/1.354015.

[64] Y. Wang, K. Duncan, E. D. Wachsman \& F. Ebrahimi. "The Effect of Oxygen Vacancy Concentration on the Elastic Modulus of Fluorite-Structured Oxides." Solid State Ionics 178 (1-2): 53-58, (2007) http://dx.doi.org/10.1016/j.ssi.2006.11.003.

[65] J. M. Schneider, K. Larsson, J. Lu, E. Olsson \& B. Hjörvarsson. "Role of Hydrogen for the Elastic Properties of Alumina Thin Films." Appl. Phys. Lett. 80 (7): 1144-1146, (2002) http://dx.doi.org/10.1063/1.1448389.

[66] R. M. Roberts, T. S. Elleman, H. Palmour \& K. Verghese. "Hydrogen Permeability of Sintered Aluminium Oxide." J. Am. Cer. Soc. 62 (9-10): 495-499, (1979) http://dx.doi.org/10.1111/j.1151-2916.1979.tb19114.x.

[67] K. P. D. Lagerlof \& R. W. Grimes. "The Defect Chemistry of Sapphire $\left(\alpha-\mathrm{Al}_{2} \mathrm{O}_{3}\right)$." $46(16)$ : 5689-5700, (1998) http://dx.doi.org/10.1016/s1359-6454(98)00256-0.

[68] T. Mathews, K. T. Jacob \& J. P. Hajra. "Electrical Transport in Magnesium Aluminate." $B$. Mater. Sci. 13 (4): 293-300, (1990) http://dx.doi.org/10.1007/bf02744986.

[69] G. Fiquet, P. Richet \& G. Montagnac. "High-temperature Thermal Expansion of Lime, Periclase, Corundum and Spinel." Phys. Chem. Miner. 27 (2): 103-111, (1999) http://dx.doi.org/10.1007/s002690050246.

[70] S. Kim, S. Wang, X. Chen, Y. L. Yaug, N. Wu, A. Ignatiev, A. J. Jacobson \& B. Abeles. "Oxygen Surface Exchange in Mixed Ionic Electronic Conductors: Application to $\mathrm{La}_{0.5} \mathrm{Sr}_{0.5} \mathrm{Fe}_{0.8} \mathrm{Ga}_{0.2} \mathrm{O}_{3-\delta}$." $\quad J$. Electrochem. Soc. $147 \quad$ (6): 2398-2406, (2000) http://dx.doi.org/10.1149/1.1393544

[71] L. Yan, K. R. Balasubramaniam, S. Wang, H. Du \& P. A. Salvador. "Effects of Crystallographic Orientation on the Oxygen Exchange Rate of $\mathrm{La}_{0.7} \mathrm{Sr}_{0.3} \mathrm{MnO}_{3}$ Thin Films." Solid State Ionics 194 (1): 9-16, (2011) http://dx.doi.org/10.1016/j.ssi.2011.05.004.

[72] M. W. Barsoum (2003). Fundamentals of Ceramics. New York, Taylor Francis.

[73] Q. Yang, R. R. Lunt \& J. D. Nicholas (2013). Low Temperature Lanthanum Strontium Ferrite Thin Film Stress and Oxygen Surface Exchange Coefficient Measurements. 224 ${ }^{\text {th }}$ Meeting of the Electrochemical Society; ECS Transactions, San Francisco, CA, The Electrochemical Society. 37-46

[74] N. Orlovskaya, H. Anderson, M. Brodnikovskyy, M. Lugovy \& M. J. Reece. "Inelastic Deformation Behavior of $\mathrm{La}_{0.6} \mathrm{Sr}_{0.4} \mathrm{FeO}_{3}$ Perovskite." J. Appl. Phys. 100 (2): 026102026101 to 026102-026104, (2006) http://dx.doi.org/10.1063/1.2218026.

[75] Y. Kimura, T. Kushi, S.-i. Hashimoto, K. Amezawa \& T. Kawada. "Influences of Temperature and Oxygen Partial Pressure on Mechanical Properties of $\mathrm{La}_{0.6} \mathrm{Sr}_{0.4} \mathrm{Co}_{1}$ -

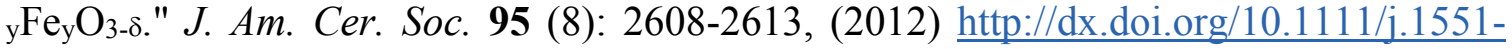
2916.2012.05265.x. 
[76] M. Kuhn, S. Hashimoto, K. Sato, K. Yashiro \& J. Mizusaki. "Thermo-chemical Lattice Expansion in $\mathrm{La}_{0.6} \mathrm{Sr}_{0.4} \mathrm{Co}_{1-\mathrm{y}} \mathrm{Fe}_{\mathrm{y}} \mathrm{O}_{3-\delta .} . "$ Solid State Ionics 241 (0): 12-16, (2013) http://dx.doi.org/10.1016/j.ssi.2013.03.023.

[77] C. H. Hsueh, L. C. De Jonghe \& C. S. Lee. "Modeling of Thermal Stresses in Joining Two Layers with Multi- and Graded Interlayers." J. Am. Ceram. Soc. 89 (1): 251-257, (2006) http://dx.doi.org/10.1111/j.1551-2916.2005.00658.x.

[78] Q. Yang. Development and Use of a New Curvature Relaxation Technique to Measure the In Situ Oxygen Surface Exchange Coefficients and Stress of Lanthanum Strontium Ferrite Films PhD Thesis, Michigan State University, (2014).

[79] M. Leonhardt, R. A. De Souza, J. Claus \& J. Maier. "Surface Kinetics of Oxygen Incorporation into $\mathrm{SrTiO}_{3} . "$ J. Electrochem. Soc. 149 (2): J19-J26, (2002) http://dx.doi.org/10.1149/1.1430723.

[80] S. R. Bishop, K. L. Duncan \& E. D. Wachsman. "Surface and Bulk Oxygen Nonstoichiometry and Bulk Chemical Expansion in Gadolinium-doped Cerium Oxide." Acta Mater. 57 (12): 3596-3605, (2009) http://dx.doi.org/10.1016/j.actamat.2009.04.017.

[81] S. R. Bishop, K. L. Duncan \& E. D. Wachsman. "Defect Equilibria and Chemical Expansion in Non-stoichiometric Undoped and Gadolinium-doped Cerium Oxide." Electrochem. Acta 54 (5): 1436-1443, (2009) http://dx.doi.org/10.1016/j.electacta.2008.09.026.

[82] H. W. Chiang, R. N. Blumenthal \& R. A. Fournelle. "A High-Temperature Lattice-Parameter and Dilatometer Study of the Defect Structure of Nonstoichiometric Cerium Dioxide." Solid State Ionics 66 (1-2): 85-95, (1993) http://dx.doi.org/10.1016/0167-2738(93)90031W.

[83] V. V. Kharton, A. A. Yaremchenko, M. V. Patrakeev, E. N. Naumovich \& F. M. B. Marques. "Thermal and Chemical Induced Expansion of $\mathrm{La}_{0.3} \mathrm{Sr}_{0.7}(\mathrm{Fe}, \mathrm{Ga}) \mathrm{O}_{3-\delta}$ Ceramics." J. Eur. Ceram. Soc. 23 (9): 1417-1426, (2003) http://dx.doi.org/10.1016/s0955-2219(02)00308-4.

[84] S. R. Bishop, K. L. Duncan \& E. D. Wachsman. "Thermo-Chemical Expansion in StrontiumDoped Lanthanum Cobalt Iron Oxide." J. Am. Cer. Soc. 93 (12): 4115-4121, (2010) http://dx.doi.org/10.1111/j.1551-2916.2010.03991.x.

[85] S. B. Adler. "Chemical Expansivity of Electrochemical Ceramics." J. Am. Cer. Soc. 84 (9): 2117-2119, (2001) http://dx.doi.org/10.1111/j.1151-2916.2001.tb00968.x.

[86] X. Y. Chen, J. S. Yu \& S. B. Adler. "Thermal and Chemical Expansion of Sr-doped Lanthanum Cobalt Oxide (La-1-x $\left.\mathrm{Sr}_{x} \mathrm{CoO}_{3-8}\right)$." Chem. Mater. 17 (17): 4537-4546, (2005) http://dx.doi.org/10.1021/cm050905h.

[87] M. Vracar, A. Kuzmin, R. Merkle, J. Purans, E. A. Kotomin, J. Maier \& O. Mathon. "JahnTeller Distortion around $\mathrm{Fe}^{4+}$ in $\mathrm{SrFe}_{\mathrm{x}} \mathrm{Ti}_{1-\mathrm{x}} \mathrm{O}_{3-\delta}$ from X-ray Absorption Spectroscopy, $\mathrm{X}$ ray Diffraction, and Vibrational Spectroscopy." Phys. Rev. B 76 (17): 174107-174101 to 174107-174110, (2007) http://dx.doi.org/10.1103/PhysRevB.76.174107.

[88] S. McIntosh, J. F. Vente, W. G. Haije, D. H. A. Blank \& H. J. M. Bouwmeester. "Oxygen Stoichiometry and Chemical Expansion of $\mathrm{Ba}_{0.5} \mathrm{Sr}_{0.5} \mathrm{Co}_{0.8} \mathrm{Fe}_{0.2} \mathrm{O}_{3-\delta}$ Measured by In Situ Neutron Diffraction." Chem. Mater. 18 (8): 2187-2193, (2006) http://dx.doi.org/10.1021/cm052763x.

[89] P. H. Larsen, P. V. Hendriksen \& M. Mogensen. "Dimensional Stability and Defect Chemistry of Doped Lanthanum Chromites." J. Therm. Anal. 49 (3): 1263-1275, (1997) http://dx.doi.org/10.1007/bf01983683.

[90] S. Miyoshi, J. O. Hong, K. Yashiro, A. Kaimai, Y. Nigara, K. Kawamura, T. Kawada \& J. Mizusaki. "Lattice Expansion upon Reduction of Perovskite-type $\mathrm{LaMnO}_{3}$ with Oxygen- 
Deficit Nonstoichiometry." Solid State Ionics 161 (3-4): 209-217, (2003) http://dx.doi.org/10.1016/s0167-2738(03)00281-9.

[91] J. E. tenElshof, M. H. R. Lankhorst \& H. J. M. Bouwmeester. "Chemical Diffusion and Oxygen Exchange of $\mathrm{La}_{0.6} \mathrm{Sr}_{0.4} \mathrm{Co}_{0.6} \mathrm{Fe}_{0.4} \mathrm{O}_{3-\delta .} . "$ Solid State Ionics 99 (1-2): 15-22, (1997) http://dx.doi.org/10.1016/S0167-2738(97)00263-4.

[92] M. Tsuchiya, N. A. Bojarczuk, S. Guha \& S. Ramanathan. "Microstructural Effects on Electrical Conductivity Relaxation in Nanoscale Ceria Thin Films." J. Chem. Phys. 130 (17): 174711-174711 to 174711-174719, (2009) http://dx.doi.org/10.1063/1.3126092.

[93] J. B. Smith \& T. Norby. "On the Steady-state Oxygen Permeation through $\mathrm{La}_{2} \mathrm{NiO}_{4+\delta}$ Membranes." $\quad J . \quad$ Electrochem $\quad$ Soc. $153 \quad$ (2): A233-A238, (2006) http://dx.doi.org/10.1149/1.2138679.

[94] S. Kim, Y. L. Yang, A. J. Jacobson \& B. Abeles. "Diffusion and Surface Exchange Coefficients in Mixed Ionic Electronic Conducting Oxides from the Pressure Dependence of Oxygen Permeation." Solid State Ionics 106 (3-4): 189-195, (1998) http://dx.doi.org/10.1016/S0167-2738(97)00492-X.

[95] M. H. R. Lankhorst \& H. J. M. Bouwmeester. "Determination of Oxygen Nonstoichiometry and Diffusivity in Mixed Conducting Oxides by Oxygen Coulometric Titration: I. Chemical Diffusion in $\mathrm{La}_{0.8} \mathrm{Sr}_{0.2} \mathrm{CoO}_{3-8 . "}$ J. Electrochem. Soc. 144 (4): 1261-1267, (1997) http://dx.doi.org/10.1149/1.1837580.

[96] S. Diethelm \& J. Van herle. "Electrochemical Characterisation of Oxygen Nonstoichiometry and Transport in Mixed Conducting Oxides - Application to La0.4 $\mathrm{Ba}_{0.6} \mathrm{Fe}_{0.8} \mathrm{Co}_{0.2} \mathrm{O}_{3-8}$." Solid State Ionics 174 (1-4): 127-134, (2004) http://dx.doi.org/10.1016/j.ssi.2004.07.028.

[97] M. Sahibzada, W. Morton, A. Hartley, D. Mantzavinos \& I. S. Metcalfe. "A Simple Method for the Determination of Surface Exchange and Ionic Transport Kinetics in Oxides." Solid State Ionics 136: 991-996, (2000) http://dx.doi.org/10.1016/s0167-2738(00)00517-8.

[98] J. Jamnik \& J. Maier. "Treatment of the Impedance of Mixed Conductors - Equivalent Circuit Model and Explicit Approximate Solutions." J. Electrochem. Soc. 146 (11): 4183-4188, (1999) http://dx.doi.org/10.1149/1.1392611.

[99] L. Wang, R. Merkle \& J. Maier. "Surface Kinetics and Mechanism of Oxygen Incorporation into $\mathrm{Ba}_{1-\mathrm{x}} \mathrm{Sr}_{\mathrm{x}} \mathrm{Co}_{\mathrm{y}} \mathrm{Fe}_{1-\mathrm{y}} \mathrm{O}_{3-\delta} \mathrm{SOFC}$ Microelectrodes." J. Electrochem. Soc. 157 (12): B1802B1808, (2010) http://dx.doi.org/10.1149/1.3494224.

[100] M. Katsuki, S. Wang, K. Yasumoto \& M. Dokiya. "The Oxygen Transport in Gd-doped Ceria." Solid State Ionics 154-155 (0): 589-595, (2002) http://dx.doi.org/10.1016/s01672738(02)00500-3.

[101] M. B. Choi, S. Y. Jeon, H. S. Yang, J. Y. Park \& S. J. Song. "Determination of Oxygen Chemical Diffusivity from Chemical Expansion Relaxation for $\mathrm{BaCo}_{0.7} \mathrm{Fe}_{0.22} \mathrm{Nb}_{0.08} \mathrm{O}_{3-\delta .}$ " J. $\begin{array}{lllll}\text { Electrochem. } & \text { Soc. } & \mathbf{1 5 8} & \text { (2): } & \text { B189-B193, }\end{array}$ http://dx.doi.org/10.1149/1.355512210.1149/1.3515070.

[102] F. Noll, W. Munch, I. Denk \& J. Maier. "SrTiO 3 as a Prototype of a Mixed Conductor. Conductivities, Oxygen Diffusion and Boundary Effects." Solid State Ionics 86-8: 711717, (1996) http://dx.doi.org/10.1016/0167-2738(96)00155-5.

[103] J. J. Kim, S. R. Bishop, N. J. Thompson, D. Chen \& H. L. Tuller. "Investigation of Nonstoichiometry in Oxide Thin Films by Simultaneous In Situ Optical Absorption and Chemical Capacitance Measurements: Pr-Doped Ceria, A Case Study." Chem. Mater. 26 (3): 1374-1379, (2014) http://dx.doi.org/10.1021/cm403066p. 
[104] E. N. Armstrong, K. L. Duncan, D. J. Oh, J. F. Weaver \& E. D. Wachsman. "Determination of Surface Exchange Coefficients of LSM, LSCF, YSZ, GDC Constituent Materials in Composite SOFC Cathodes." J. Electrochem. Soc. 158 (5): B492-B499, (2011) http://dx.doi.org/10.1149/1.3555122.

[105] R. Moreno, P. García, J. Zapata, J. Roqueta, J. Chaigneau \& J. Santiso. "Chemical Strain Kinetics Induced by Oxygen Surface Exchange in Epitaxial Films Explored by TimeResolved X-ray Diffraction." Chem. Mater., (2013) http://dx.doi.org/10.1021/cm401714d.

[106] E. M. Hopper, E. Perret, B. J. Ingram, H. You, K.-C. Chang, P. M. Baldo, P. H. Fuoss \& J. A. Eastman. "Oxygen Exchange in $\mathrm{La}_{0.6} \mathrm{Sr}_{0.4} \mathrm{Co}_{0.2} \mathrm{Fe}_{0.8} \mathrm{O}_{3-\delta}$ Thin-Film Heterostructures under Applied Electric Potential." J. Phys. Chem. C 119 (34): 19915-19921, (2015) http://dx.doi.org/10.1021/acs.jpcc.5b05505.

[107] R. A. De Souza \& J. A. Kilner. "Oxygen Transport in $\mathrm{La}_{1-\mathrm{x}} \mathrm{Sr}_{\mathrm{x}} \mathrm{Mn}_{1-\mathrm{y}} \mathrm{Co}_{\mathrm{y}} \mathrm{O}_{3+/-\delta}$ Perovskites: Part II. Oxygen Surface Exchange." Solid State Ionics 126 (1-2): 153-161, (1999) http://dx.doi.org/10.1016/S0167-2738(99)00228-3.

[108] R. J. Chater, S. Carter, J. A. Kilner \& B. C. H. Steele. "Development of a Novel SIMS Technique for Oxygen Self-Diffusion and Surface Exchange Coefficient Measurements in Oxides of Hihg Diffusivity." Solid State Ionics 53: 859-867, (1992) http://dx.doi.org/10.1016/0167-2738(92)90266-r. 